Western University

Scholarship@Western

8-22-2016

\title{
Selective Oxygen Atom Insertion into an Aryl-Palladium Bond
}

Ava Behnia

The University of Western Ontario

Paul D. Boyle

The University of Western Ontario

Johanna M. Blacquiere

The University of Western Ontario, jblacqu2@uwo.ca

Richard J. Puddephatt

The University of Western Ontario

Follow this and additional works at: https://ir.lib.uwo.ca/chempub

Part of the Chemistry Commons

Citation of this paper:

Ava Behnia, Paul D. Boyle, Johanna M. Blacquiere, and Richard J. Puddephatt Organometallics 2016 35(16), 2645-2654

DOI: $10.1021 /$ acs.organomet.6b00387 


\title{
Selective Oxygen Atom Insertion into an Aryl-Palladium Bond
}

Ava Behnia, Paul D. Boyle, Johanna M. Blacquiere,* Richard J. Puddephatt*

Department of Chemistry, University of Western Ontario, London, Canada N6A 5B7

*Corresponding authors. E-mail: johanna.blacquiere@uwo.ca (JMB), pudd@uwo.ca (RJP)

\begin{abstract}
The chemistry of a palladium(II) complex containing both an alkyl- and an aryl-palladium bond is reported. The reaction of $\left[\mathrm{Pd}\left(\mathrm{CH}_{2} \mathrm{CMe}_{2} \mathrm{C}_{6} \mathrm{H}_{4}\right)(\mathrm{MesN}=\mathrm{CH}-\mathrm{CH}=\mathrm{NMes})\right]$ with bromine or iodine leads to reductive elimination of 1,1-dimethylcyclobutabenzene with formation of $\left[\mathrm{PdX}_{2}(\mathrm{MesN}=\mathrm{CH}-\mathrm{CH}=\mathrm{NMes})\right], \mathrm{X}=\mathrm{Br}$ or I. However, the reaction with hydrogen peroxide gives $\left[\mathrm{Pd}\left(\mathrm{CH}_{2} \mathrm{CMe}_{2} \mathrm{C}_{6} \mathrm{H}_{4} \mathrm{O}\right)(\mathrm{MesN}=\mathrm{CH}-\mathrm{CH}=\mathrm{NMes})\right]$ by overall oxygen atom insertion into the aryl-palladium rather than the alkyl-palladium bond. This complex $\left[\mathrm{Pd}\left(\mathrm{CH}_{2} \mathrm{CMe}_{2} \mathrm{C}_{6} \mathrm{H}_{4} \mathrm{O}\right)(\mathrm{MesN}=\mathrm{CH}-\mathrm{CH}=\mathrm{NMes})\right]$ reacts with bromine, iodine or hydrogen peroxide to give 3,3-dimethyl-2,3-dihydro-benzofuran and the corresponding complex $\left[\mathrm{PdX}_{2}(\mathrm{MesN}=\mathrm{CH}-\mathrm{CH}=\mathrm{NMes})\right]$. The mechanisms of reaction and basis for selectivity are discussed. The results support the view that oxygen-atom insertion is a mechanistically viable pathway for selective catalytic oxidation of hydrocarbons by the green oxidant hydrogen peroxide.
\end{abstract}

\section{Introduction}

The development of organopalladium(IV) chemistry in recent years has been impressive, and has stimulated research into catalysis involving $\mathrm{Pd}(\mathrm{II}) / \mathrm{Pd}(\mathrm{IV})$ cycles to complement the many important catalytic reactions involving $\mathrm{Pd}(0) / \mathrm{Pd}(\mathrm{II})$ cycles. ${ }^{1,2}$ The higher oxidation state catalysis has greatest potential in reactions carried out under oxidizing conditions, including the functionalization of hydrocarbons to form oxygenated or halogenated derivatives. ${ }^{1-3}$ These catalytic reactions typically contain steps involving oxidation of palladium(II) to palladium(IV) by oxygen, halogen or their equivalents (i.e. peroxide or hypervalent halide oxidants), followed by reductive elimination involving $\mathrm{C}-\mathrm{O}$ or $\mathrm{C}-\mathrm{X}(\mathrm{X}=$ halogen $)$ bond formation. It is therefore important to understand the factors that influence reactivity and selectivity in these reactions. ${ }^{1-3}$

Palladium(IV) complexes containing both $\mathrm{Pd}-\mathrm{C}\left(\mathrm{sp}^{3}\right)$ and $\mathrm{Pd}-\mathrm{C}\left(\mathrm{sp}^{2}\right)$ bonds, such as $\boldsymbol{A}$ (Scheme 1), allow a direct study of selectivity in reductive elimination. ${ }^{4-6}$ The Sanford group has 
shown that the first step in the reductive elimination from $\boldsymbol{A}$ is dissociation of the ligand $\mathrm{X}^{-}$(e.g. $\mathrm{X}^{-}=\mathrm{PhO}^{-}, \mathrm{NO}_{3}^{-}, \mathrm{OTs}^{-}, \mathrm{NHTs}^{-}$) to give a 16-electron 5-coordinate intermediate $\boldsymbol{B}$. This $\mathrm{Pd}(\mathrm{IV})$ intermediate can undergo reduction to $\mathrm{Pd}(\mathrm{II})$ through three possible routes: 1) nucleophilic attack by $\mathrm{X}^{-}$gives $\boldsymbol{C}$ with $\mathrm{CH}_{2}-\mathrm{X}$ bond formation; 2) concerted intramolecular reductive elimination with $\mathrm{CH}_{2}-\mathrm{F}$ bond formation gives $\boldsymbol{D}$; or 3 ) reductive elimination of $\mathrm{C}-\mathrm{C}$ gives 1,1dimethylcyclobutabenzene and $\boldsymbol{E}$. The 14-electron complexes $\boldsymbol{D}$ or $\boldsymbol{E}$ undergo further coordination with $\mathrm{X}^{-}$to give square planar 16-electron palladium(II) complexes. The selectivity in the reductive elimination is dependent on the nature of the anion $\mathrm{X}^{-4}$.

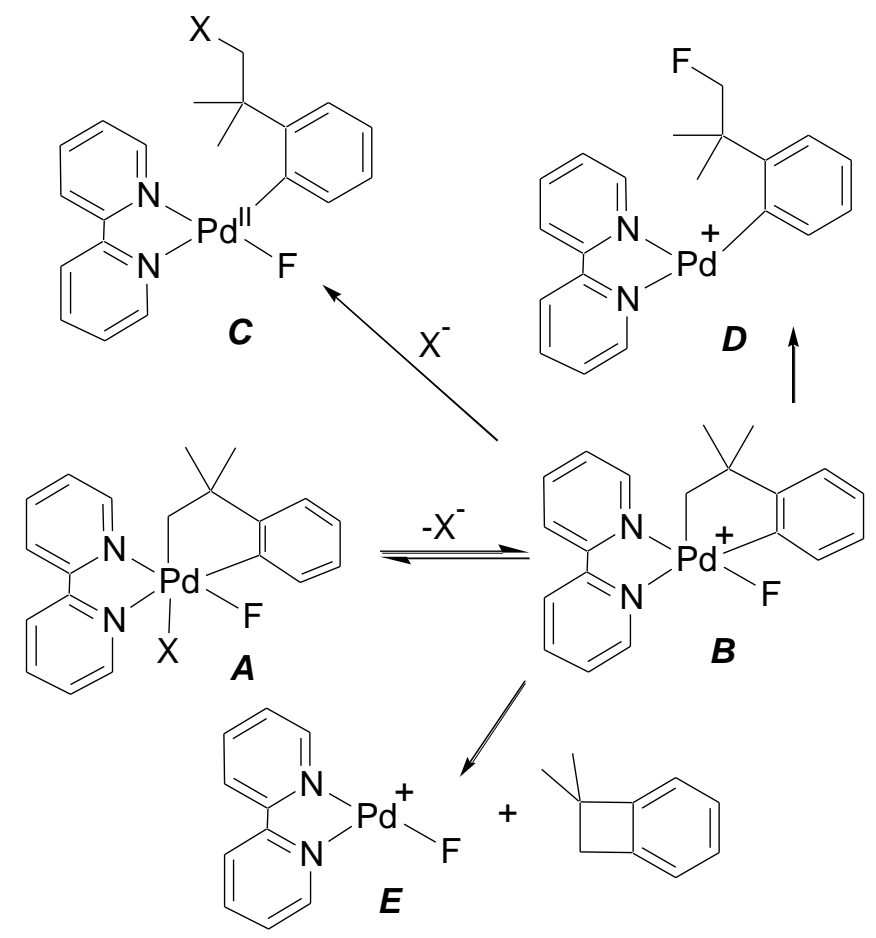

Scheme 1. Competition between $\mathrm{C}-\mathrm{X}(\mathrm{X}=\mathrm{OR}$ or NHR), C-F and $\mathrm{C}-\mathrm{C}$ reductive elimination from the palladium(IV) complex $\boldsymbol{A}^{4}{ }^{4}$

The Mirica group showed that the palladium(II) complex $\boldsymbol{F}$ (Scheme 2) was easily oxidized by oxygen or hydrogen peroxide to give the stable hydroxopalladium(IV) complex $\boldsymbol{G}$, from which, on heating to $110{ }^{\circ} \mathrm{C}$ in dimethylsulfoxide solution, reductive elimination occurred to give a complex which was formulated as $\boldsymbol{H} .^{5}$ In contrast to the Sanford complexes of Scheme $1,{ }^{4}$ the reductive elimination from $\boldsymbol{G}$ involves selective $\mathrm{C}\left(\mathrm{sp}^{2}\right)-\mathrm{O}$ rather than $\mathrm{C}\left(\mathrm{sp}^{3}\right)-\mathrm{O}$ bond formation, probably by a concerted intramolecular mechanism. ${ }^{5}$ The tentatively assigned intermediate $\mathbf{H}$ subsequently reacts with acid to give 2-t-butylphenol. Protonolysis of a metal-carbon bond in the 
related compound $\left[\mathrm{Pd}\left(\mathrm{CH}_{2} \mathrm{CMe}_{2} \mathrm{C}_{6} \mathrm{H}_{4}\right)\left(\mathrm{PMe}_{3}\right)_{2}\right]$ with phosphine instead of amine donor ligands is proposed to occur through a transient hydridopalladium(IV) intermediate and can lead to cleavage of either the $\mathrm{Pd}-\mathrm{C}\left(\mathrm{sp}^{3}\right)$ or $\mathrm{Pd}-\mathrm{C}\left(\mathrm{sp}^{2}\right)$ bond, though the latter is favored kinetically. ${ }^{6 \mathrm{a}}$

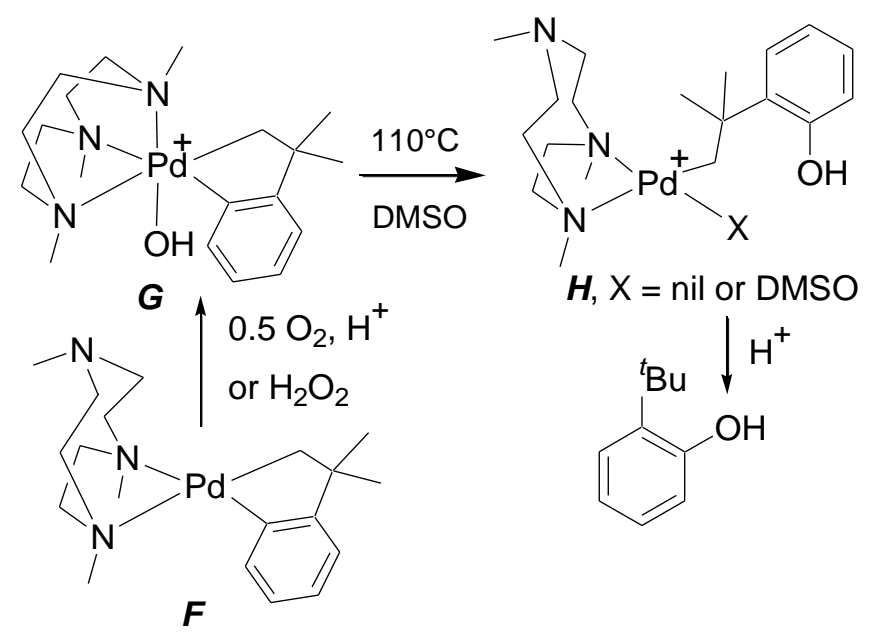

Scheme 2. Reductive elimination with selective aryl C-O bond formation. ${ }^{5}$

These observations show that the nature of the supporting ligands play a key role in controlling selectivity of $\mathrm{sp}^{2}$ or $\mathrm{sp}^{3} \mathrm{C}-\mathrm{X}$ bond formation. The Me $\mathrm{MACN}_{3}$ and hydroxo ligands in $\boldsymbol{G}$ (Scheme 2) do not easily dissociate so reaction is proposed to occur directly from the 6coordinate 18-electron complex. ${ }^{5}$ However, the $\mathrm{X}^{-}$ligand in $\boldsymbol{A}$ (Scheme 1), which is trans to a high trans-influence alkyl group, dissociates reversibly and, as is established for several related palladium(IV) and platinum(IV) complexes, ${ }^{1,7}$ the reductive elimination occurs more easily from the 16-electron intermediate $\boldsymbol{B}{ }^{4}$

The commonly acknowledged pathways for reductive C-O bond formation include a step-wise nucleophilic attack (i.e. Scheme 1) or a concerted pathway. A third, less well studied, pathway involves overall oxygen-atom insertion into a Pd-C bond. Hillhouse found that treatment of the nickel(II) complex $\boldsymbol{I}$ with nitrous oxide afforded a $\mathrm{Ni}(\mathrm{II}) \operatorname{dimer} \boldsymbol{J}$ with an oxygen atom inserted selectively into the Ni-C(sp${ }^{2}$ ) bond (Scheme 3$){ }^{8}$ Oxidation of the monomer $\boldsymbol{K}$ with iodine leads to formation of the diiodonickel(II) complex $\boldsymbol{L}$ and the benzofuran derivative BF, through $\mathrm{C}\left(\mathrm{sp}^{3}\right)$-O reductive elimination. 


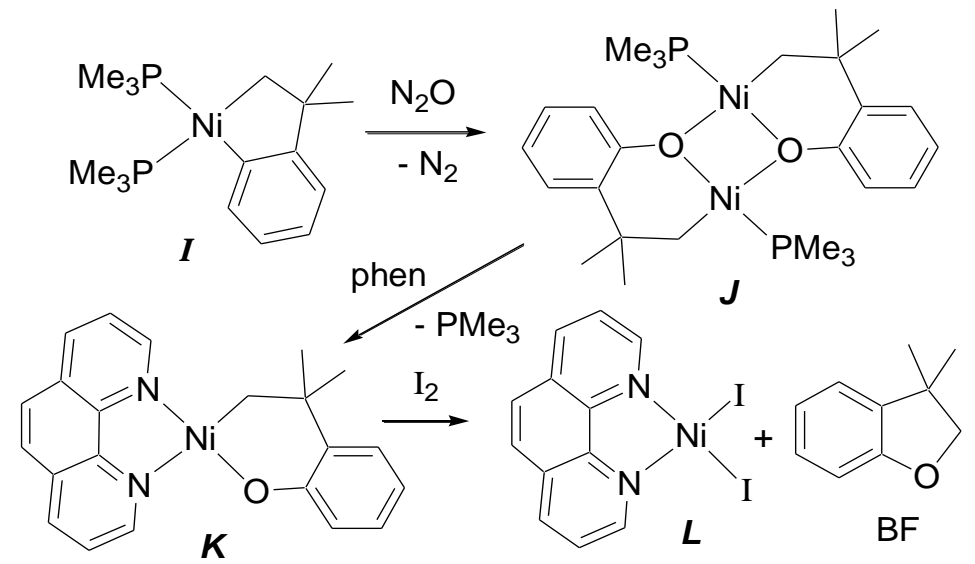

Scheme 3. Precedent for O-atom insertion into M-Ar from organonickel chemistry. ${ }^{8}$

Oxygen atom insertion into arylpalladium or arylrhodium bonds has also been established in complexes where no alkylpalladium bond is present (Scheme 4). Several oxygen atom donors could be used but, in most cases, oxidation with hydrogen peroxide or $t$-butyl hydroperoxide required an iron(III) or vanadium(IV) catalyst (Scheme 4). ${ }^{9}$ The mechanism was proposed to involve a transient oxopalladium(IV) intermediate, whose possible nature has recently been probed theoretically. ${ }^{10}$ Only with ligand assistance has the direct reaction with hydrogen peroxide in water been observed (Scheme 5). ${ }^{3 a}$
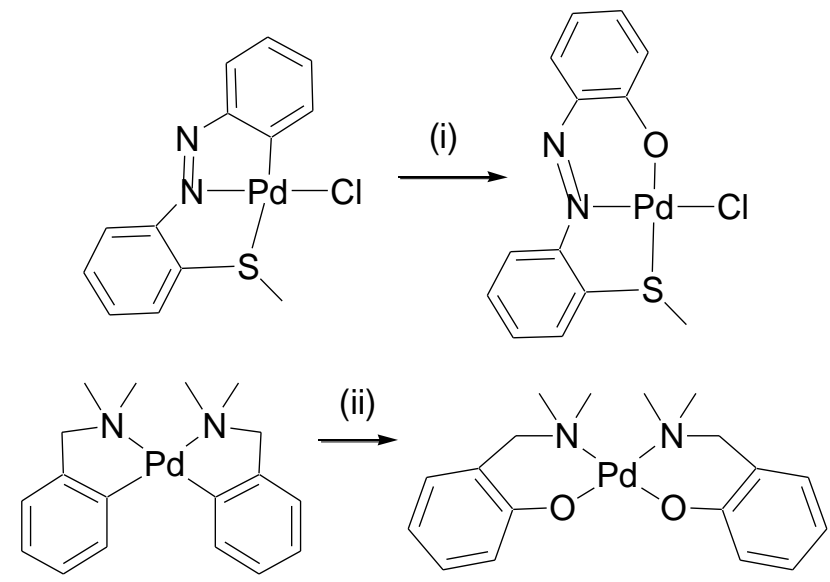

Scheme 4. Examples of oxygen atom insertion. Reagents: (i) MCPBA, $\mathrm{C}_{6} \mathrm{~F}_{5} \mathrm{IO}$ or $\mathrm{H}_{2} \mathrm{O}_{2} / \mathrm{Fe}(\mathrm{III})$ catalyst; (ii) $t$ - $\mathrm{BuOOH} /\left[\mathrm{V}(\mathrm{O})(\mathrm{acac})_{2}\right]$ catalyst. $^{9}$ 


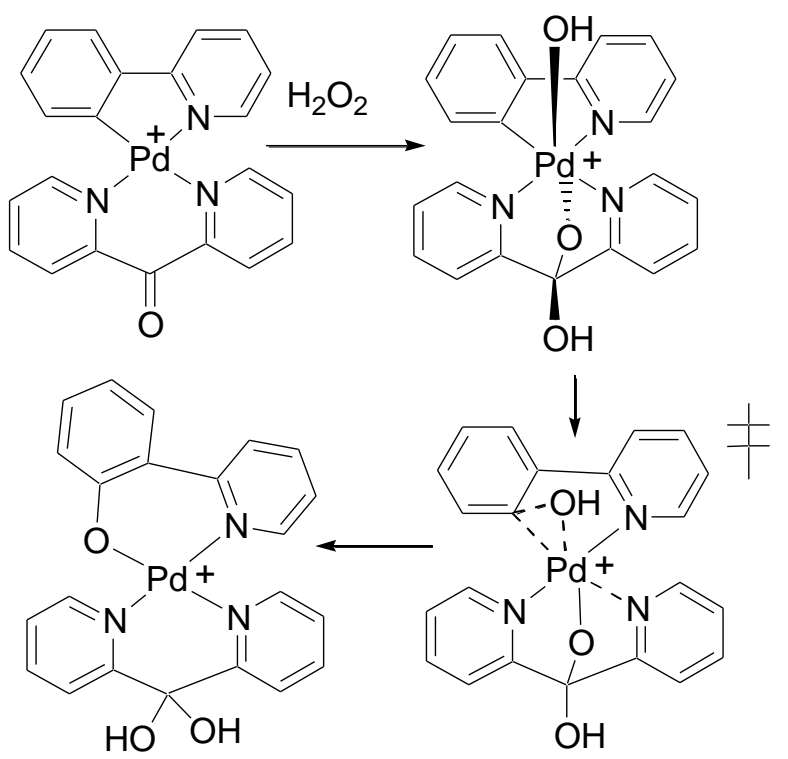

Scheme 5. Ligand assisted reaction with $\mathrm{H}_{2} \mathrm{O}_{2}{ }^{3 \mathrm{a}}$

Recently, the hydroxylation of arenes using $\mathrm{O}_{2}$ or $\mathrm{H}_{2} \mathrm{O}_{2}$ as the environmentally benign oxidant and $\mathrm{O}$-atom source has been achieved, with some examples using palladium(II) catalysts. ${ }^{11}$ The identification of the operative pathway for $\mathrm{C}-\mathrm{O}$ bond formation is critical for the continued optimization of catalytic functionalization of both arenes and alkanes. ${ }^{1-3}$ Herein, we study the reactions of a palladium(II) complex $\left[\mathrm{Pd}\left(\mathrm{CH}_{2} \mathrm{CMe}_{2} \mathrm{C}_{6} \mathrm{H}_{4}\right)(\mathrm{MesN}=\mathrm{CH}-\mathrm{CH}=\mathrm{NMes})\right]$ with the oxidants $\mathrm{H}_{2} \mathrm{O}_{2}$ and halogens. We chose the diimine ligand $\mathrm{MesN}=\mathrm{CH}-\mathrm{CH}=\mathrm{NMes}{ }^{12}$ on the basis that the nitrogen donors will allow oxidation to the Pd(IV) state (compare Schemes 1 and 2), ${ }^{4,5}$ while the steric bulk of the $N$-mesityl substituents will promote reductive elimination. The reactions lead to $\mathrm{C}-\mathrm{O}$ and $\mathrm{C}-\mathrm{C}$ bond formation from the palladacycle, including selective oxygen atom insertion from the hydrogen peroxide oxidant.

\section{Results and Discussion}

The complex $\left[\mathrm{Pd}\left(\mathrm{CH}_{2} \mathrm{CMe}_{2} \mathrm{C}_{6} \mathrm{H}_{4}\right)(\mathrm{MesN}=\mathrm{CH}-\mathrm{CH}=\mathrm{NMes})\right]$, 1, was prepared by ligand exchange from the corresponding 1,5-cyclooctadiene complex $\left[\mathrm{Pd}\left(\mathrm{CH}_{2} \mathrm{CMe}_{2} \mathrm{C}_{6} \mathrm{H}_{4}\right)(\mathrm{COD})\right]^{5,6}$ and $\mathrm{MesN}=\mathrm{CH}-\mathrm{CH}=\mathrm{NMes}^{12}$ according to equation (1). The best yield of $75 \%$ was obtained by carrying out the reaction in ether solution at $-65^{\circ} \mathrm{C}$ for 17 hours. Once obtained in pure form, complex 1 was thermally stable and could be stored at room temperature in air for extended periods. In order to facilitate subsequent reaction monitoring of $\mathbf{1}$, a complete assignment of the 
${ }^{1} \mathrm{H}$ and ${ }^{13} \mathrm{C}$ NMR spectra of the complex was made by using a combination of correlated ${ }^{1} \mathrm{H}-{ }^{1} \mathrm{H}$ COSY and ${ }^{1} \mathrm{H}_{-}{ }^{13} \mathrm{C}$ HSQC and HMBC NMR spectra. Complex 1 has effective $C_{s}$ symmetry and its ${ }^{1} \mathrm{H}$ NMR spectrum contained two singlet imine resonances at $\delta 7.06$ and 7.05 and two sets of mesityl resonances. The $\mathrm{CH}_{2}$ and $\mathrm{CMe}_{2}$ resonances of the hydrocarbon ligand appeared at $\delta 2.48$ and 1.49 respectively.

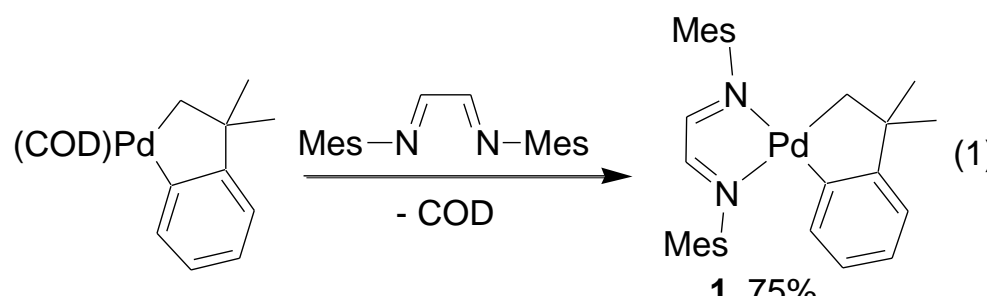

The structure of complex $\mathbf{1}$ was determined and is shown in Figure 1. Along with a molecule of ether, there are two independent but similar molecules of $\mathbf{1}$ found in the unit cell, designated by $\operatorname{Pd}(1)$ and $\operatorname{Pd}(2)$. Both molecules are square planar with very small values of Houser's $\tau_{4}$ parameter of 0.053 and $0.042\left(\tau_{4}=0\right.$ for an ideal square planar complex). ${ }^{13} \mathrm{~A}$ significant difference between the two molecules is in the degree of non-planarity of the metallacycle formed with the hydrocarbon ligand. In the $\mathrm{Pd}(2)$ molecule $\mathrm{C}(6 \mathrm{~B})$ and $\mathrm{C}(7 \mathrm{~B})$ are displaced out of the square plane by 0.33 and $0.77 \AA$, respectively. In $\operatorname{Pd}(1)$, a higher degree of distortion by $0.10 \AA$ is observed for both $\mathrm{C}(6 \mathrm{~A})$ and $\mathrm{C}(7 \mathrm{~A})$. A difference in the twist angles of the mesityl groups with respect to the square plane of the palladium centre is also observed between $\operatorname{Pd}(1)$ and $\operatorname{Pd}(2)$. The angle between the square plane and the two mesityl planes are 77 and $91^{\circ}$ for the $\operatorname{Pd}(1)$ molecule and 79 and $78^{\circ}$ for the $\operatorname{Pd}(2)$ molecule.
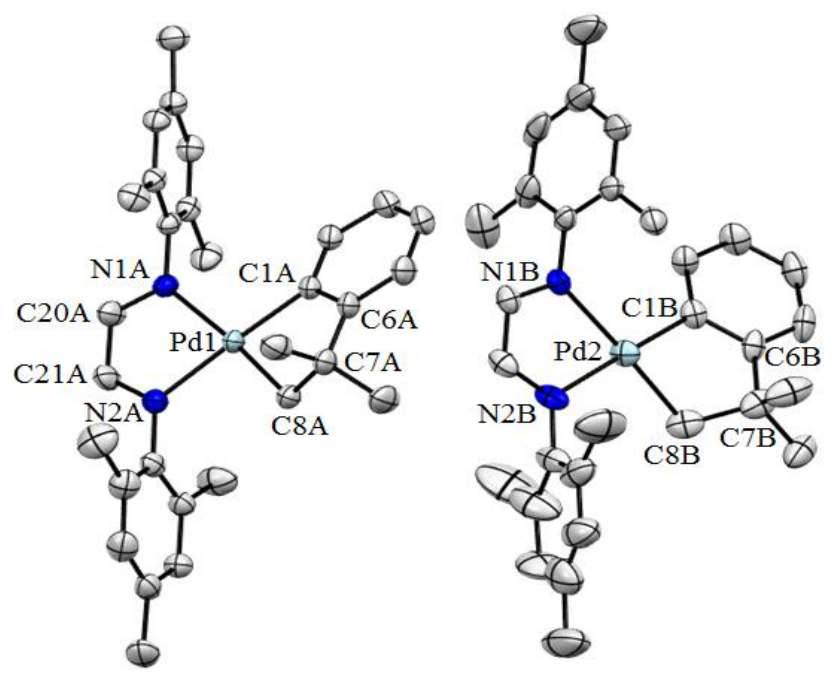
Figure 1. The structures of the two independent molecules of complex 1, showing 30\% probability ellipsoids. Selected bond parameters: $\operatorname{Pd}(1) C(1 \mathrm{~A}) 1.994(4) ; \operatorname{Pd}(1) \mathrm{C}(8 \mathrm{~A}) 2.018(4)$; $\operatorname{Pd}(1) \mathrm{N}(1 \mathrm{~A}) 2.170(3) ; \mathrm{Pd}(1) \mathrm{N}(2 \mathrm{~A}) 2.119$ (3) $\AA$; $\mathrm{C}(1 \mathrm{~A}) \operatorname{Pd}(1) \mathrm{C}(8 \mathrm{~A})$ 79.42(16); N(2A)Pd(1)N(1A) 76.82(12) ${ }^{\circ} ; \operatorname{Pd}(2) \mathrm{C}(1 \mathrm{~B})$ 1.993(4); $\operatorname{Pd}(2) \mathrm{C}(8 \mathrm{~B})$ 2.039(5); $\operatorname{Pd}(2) \mathrm{N}(2 \mathrm{~B})$ 2.117(3); $\operatorname{Pd}(2) \mathrm{N}(1 \mathrm{~B})$ 2.158(3) $\AA$; C (1B) $\operatorname{Pd}(2) \mathrm{C}(8 \mathrm{~B}) 79.43(18) ; \mathrm{N}(2 \mathrm{~B}) \operatorname{Pd}(2) \mathrm{N}(1 \mathrm{~B}) 76.57(13)^{\circ}$.

The reaction of complex 1 with bromine or iodine occurred largely according to equation (2) to give 1,1-dimethylcyclobutabenzene (CB) and the corresponding palladium(II) complex $\left[\mathrm{PdX}_{2}(\mathrm{MesN}=\mathrm{CH}-\mathrm{CH}=\mathrm{NMes})\right], \mathbf{2 a}, \mathrm{X}=\mathrm{Br}$, or $\mathbf{2 b}, \mathrm{X}=\mathrm{I}$. The 1,1-dimethylcyclobutabenzene, which was characterized by its ${ }^{1} \mathrm{H}$ NMR and mass spectra, ${ }^{4 b, 14}$ is presumed to be formed by reductive elimination, with $\mathrm{C}-\mathrm{C}$ bond formation, from a palladium(IV) intermediate by analogy with the mechanism of Scheme $1 .{ }^{4}$ However, when the reaction was monitored by ${ }^{1} \mathrm{H}$ NMR spectroscopy, no palladium(IV) complex was detected so this presumed intermediate is transient. The complexes $\mathbf{2} \mathbf{a} / \mathbf{b}$ have effective $C_{2 v}$ symmetry and, in contrast to $\mathbf{1}$, the ${ }^{1} \mathrm{H}$ NMR spectra contained only one imine resonance and one set of mesityl resonances.

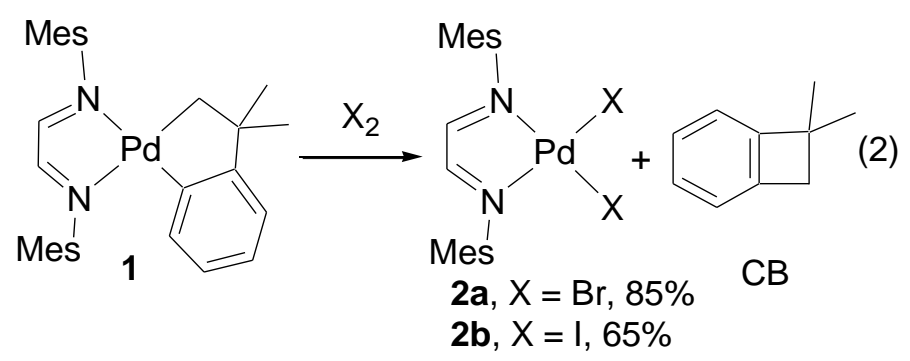

The structures of $\mathbf{2 a}$ and $\mathbf{2 b}$ were determined and are shown in Figure 2. Both structures are square planar $\left(\tau_{4}: \mathbf{2} \mathbf{a}=0.00, \mathbf{2} \mathbf{b}=0.079\right)$. In the structure of $\mathbf{2 a}$ the molecule contains a crystallographic 2-fold rotation axis. The structure of $\mathbf{2 b}$ is more complex and the repeat unit has the formula $(\mathbf{2} \mathbf{b})_{3}$.(acetone) $)_{2}$, with three independent but similar molecules of $\mathbf{2} \mathbf{b}$, of which only the $\operatorname{Pd}(1)$ molecule is shown in Figure 2. 

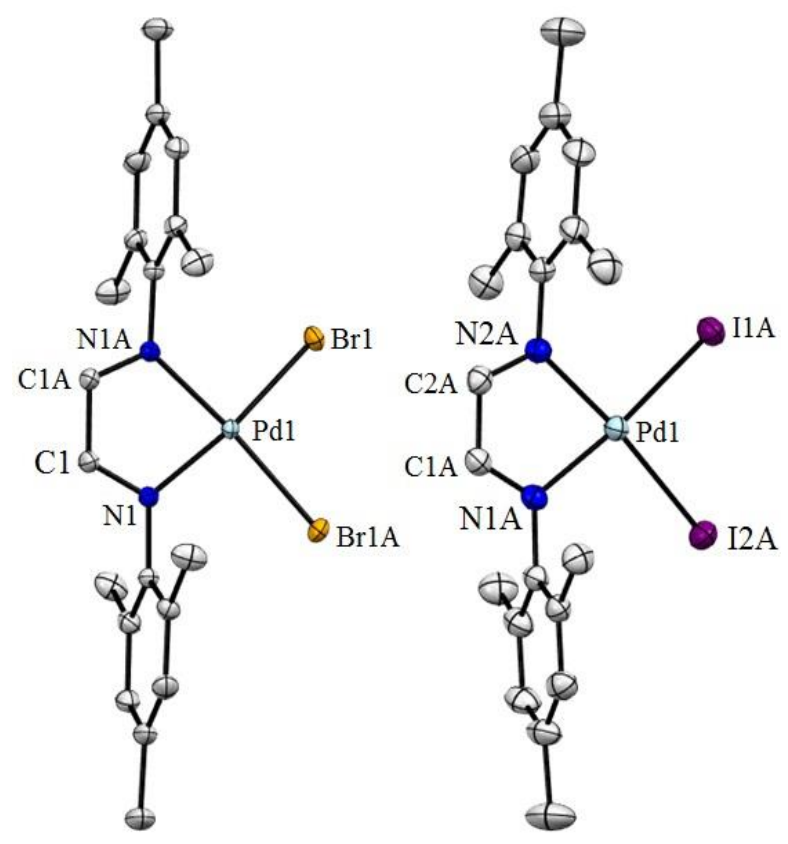

Figure 2. The structures of complexes $\mathbf{2 a}$ and $\mathbf{2 b}$, with ellipsoids shown at the $50 \%$ probability level. $\quad$ Selected bond parameters: 2a, $\operatorname{Pd}(1) \mathrm{N}(1)$ 2.023(3); $\operatorname{Pd}(1) \operatorname{Br}(1) \quad 2.4085(5) \quad \AA$ $\mathrm{N}(1) \operatorname{Pd}(1) \mathrm{N}(1 \mathrm{~A})$ 79.92(14); $\operatorname{Br}(1) \operatorname{Pd}(1) \operatorname{Br}(1)$ 93.47(3) $;$ 2b, $\operatorname{Pd}(1) \mathrm{N}(1 \mathrm{~A})$ 2.065(2); $\operatorname{Pd}(1) \mathrm{N}(2 \mathrm{~A})$ 2.069(2); $\quad \operatorname{Pd}(1) \mathrm{I}(2 \mathrm{~A}) \quad 2.5668(5) ; \quad \operatorname{Pd}(1) \mathrm{I}(1 \mathrm{~A}) \quad 2.5700(5) \quad \AA \quad \mathrm{N}(1 \mathrm{~A}) \operatorname{Pd}(1) \mathrm{N}(2 \mathrm{~A}) \quad 79.03(9)$; $\mathrm{I}(2 \mathrm{~A}) \operatorname{Pd}(1) \mathrm{I}(1 \mathrm{~A}) 90.437(17)^{\circ}$.

The reaction of complex 1 with hydrogen peroxide occurred, with different selectivity from the reactions with halogens, according to equation (3). The reaction to give the product $\left[\mathrm{Pd}\left(\mathrm{CH}_{2} \mathrm{CMe}_{2} \mathrm{C}_{6} \mathrm{H}_{4} \mathrm{O}\right)(\mathrm{MesN}=\mathrm{CH}-\mathrm{CH}=\mathrm{NMes})\right], \mathbf{3}$, occurs by selective oxygen atom insertion into the arylpalladium bond. The product is analogous to that observed previously by Hillhouse ${ }^{8}$ on oxidation of $\mathrm{Ni}(\mathrm{II})$ complexes with $\mathrm{N}_{2} \mathrm{O}$ (Scheme 3). To identify the optimal reaction conditions the conversion was monitored by ${ }^{1} \mathrm{H}$ NMR spectroscopy by following the diagnostic imine singlets of $\mathbf{1}$ and $\mathbf{3}$ (Table 1 and Figure 3). The conversion to $\mathbf{3}$ is highest in more polar solvents (Table 1, Entries 1-4), suggesting a charge-separated species is important in the formation of 3. Alternatively, the more polar solvent may promote miscibility of the $\mathrm{H}_{2} \mathrm{O}_{2}$ solution $\left(30 \%\right.$ in $\left.\mathrm{H}_{2} \mathrm{O}\right)$. Using acetone as the optimal solvent the reaction time was increased from 1 to $3 \mathrm{~h}$, giving a maximum conversion of 82\% (Entry 5). The formation of $\mathbf{3}$ is thus considerably slower than reaction of $\mathbf{1}$ with the halogens to give $\mathbf{2} \mathbf{a} / \mathbf{b}$ (eq. 2), in which a dramatic colour change is observed within minutes. Different equivalents of $\mathrm{H}_{2} \mathrm{O}_{2}$ in the range of 1 to 4 
were tested (Entries 5-9), revealing that two equivalents are optimal. The decrease in observed yield of $\mathbf{3}$ with greater equivalents is notable in the context of catalytic applications where an oxidant is used in considerable excess to the catalyst. Here, the low conversion with higher equivalents is, at least in part, due to subsequent reactivity of $\mathbf{3}$ to release the organic ligand as a benzofuran product (vide infra). The optimization reveals that the maximum conversion to $\mathbf{3}$ (82\%) is achieved in acetone with 2 equivalents of $\mathrm{H}_{2} \mathrm{O}_{2}$ in a reaction time of three hours, and the isolated yield was $50 \%$ under these conditions.

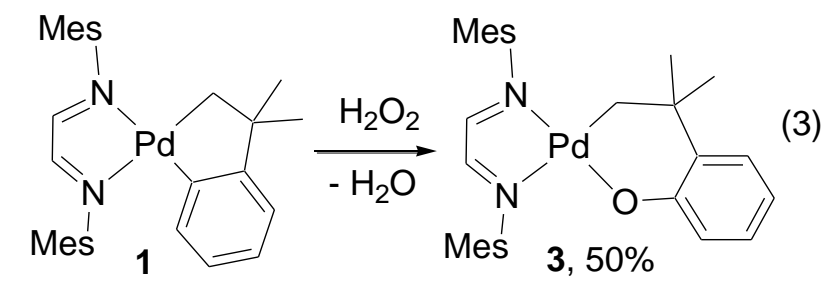

Table 1. Optimization of the formation of $\mathbf{3}$ from $\mathbf{1}$ at room temperature. ${ }^{\mathrm{a}}$

\begin{tabular}{cccccc}
\hline Entry & Solvent & $\varepsilon^{\mathrm{b}}$ & Time $(\mathrm{h})$ & $\mathbf{1}: \mathrm{H}_{2} \mathrm{O}_{2}$ & $\mathbf{3}(\%)^{\mathrm{c}}$ \\
\hline 1 & $\left(\mathrm{CD}_{3}\right)_{2} \mathrm{CO}$ & 20.7 & 1 & $1: 2$ & 67 \\
2 & $\mathrm{CD}_{2} \mathrm{Cl}_{2}$ & 8.9 & 1 & $1: 2$ & 33 \\
3 & $\mathrm{CDCl}_{3}$ & 4.8 & 1 & $1: 2$ & 40 \\
4 & $\mathrm{C}_{6} \mathrm{D}_{6}$ & 2.2 & 1 & $1: 2$ & 21 \\
5 & $\left(\mathrm{CD}_{3}\right)_{2} \mathrm{CO}$ & 20.7 & 3 & $1: 2$ & 82 \\
6 & $\left(\mathrm{CD}_{3}\right)_{2} \mathrm{CO}$ & 20.7 & 3 & $1: 1$ & 43 \\
7 & $\left(\mathrm{CD}_{3}\right)_{2} \mathrm{CO}$ & 20.7 & 3 & $1: 1.5$ & 62 \\
8 & $\left(\mathrm{CD}_{3}\right)_{2} \mathrm{CO}$ & 20.7 & 3 & $1: 3$ & 40 \\
9 & $\left(\mathrm{CD}_{3}\right)_{2} \mathrm{CO}$ & 20.7 & 3 & $1: 4$ & 37 \\
\hline
\end{tabular}

\footnotetext{
${ }^{a}$ All reactions were carried out under air and at room temperature (see experimental for details).

${ }^{b}$ Dielectric constant of solvent; ${ }^{c}$ The yield of $\mathbf{3}$ was calculated by integration of its imine resonances relative to the internal standard 1,3,5-trimethoxybenzene.
} 


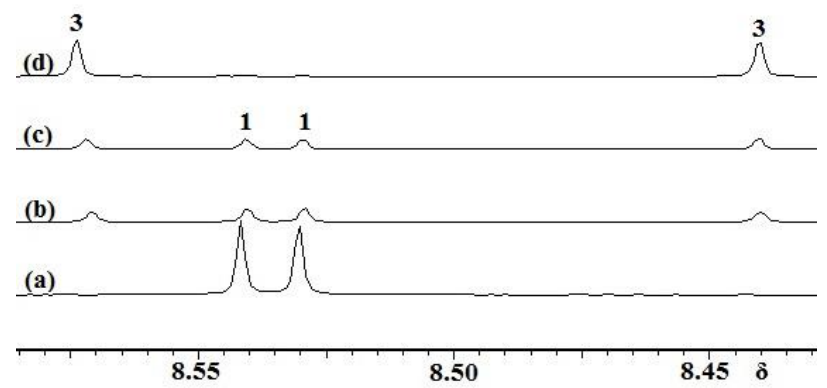

Figure 3. ${ }^{1} \mathrm{H}$ NMR spectra in the region of the imine protons during reaction of complex 1 with 2 eq $\mathrm{H}_{2} \mathrm{O}_{2}$ in $\left(\mathrm{CD}_{3}\right)_{2} \mathrm{CO}$ at room temperature to give complex 3. Spectra depict a) authentic 1; and the reaction mixture of 1 and $\mathrm{H}_{2} \mathrm{O}_{2}$ after (b) 10 min., (c) $2 \mathrm{~h}$., and (d) $3 \mathrm{~h}$.

Compound 3 was fully characterized by ${ }^{1} \mathrm{H}$ and ${ }^{13} \mathrm{C}$ NMR and IR spectroscopies, mass spectrometry, elemental analysis and X-ray crystallography. The ${ }^{1} \mathrm{H}$ NMR spectrum gives two sets of imine and mesityl resonances indicating that $\mathbf{3}$ has $C_{s}$ symmetry (Figure 3). The singlet resonances for $\mathrm{CH}_{2}$ and $\mathrm{CMe}_{2}$ are found at $\delta 1.73$ and 1.10, respectively, upfield of those found for 1 .

The structure of complex $\mathbf{3}$ was determined as the benzene solvate and is shown in Figure 4. The structure confirms the selectivity for $\mathrm{O}$-atom insertion is for the $\mathrm{Pd}-\mathrm{C}\left(\mathrm{sp}^{2}\right)$ bond. The 6membered $\mathrm{PdC}_{4} \mathrm{O}$ ring adopts a twist chair conformation, with the atom $\mathrm{C}(6)$ having the highest displacement of $0.64 \AA$ from the palladium square plane. The two mesityl rings are twisted out of the square plane of the palladium diimine ring by 67 and $79^{\circ}$. 


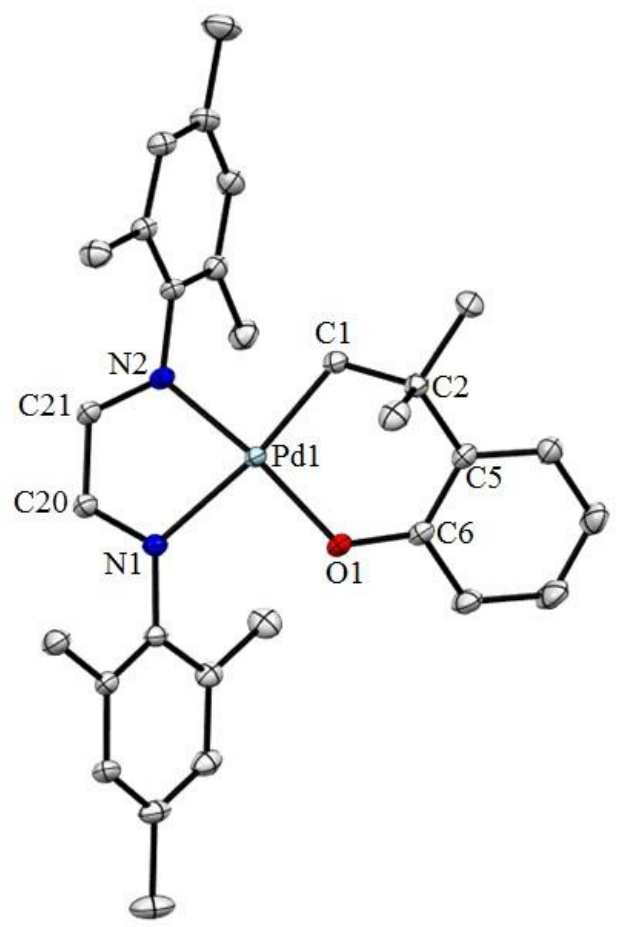

Figure 4. A view of the structure of complex 3 (ellipsoids at 50\% probability). Co-crystallized benzene and hydrogen atoms are not shown, for clarity. Selected bond parameters: $\mathrm{Pd}(1) \mathrm{O}(1)$ 1.9900(10); $\operatorname{Pd}(1) \mathrm{C}(1)$ 2.0124(12); $\operatorname{Pd}(1) \mathrm{N}(2)$ 2.0187(11); $\mathrm{Pd}(1) \mathrm{N}(1) 2.1685(10) \AA ̊$ $\mathrm{O}(1) \operatorname{Pd}(1) \mathrm{C}(1)$ 92.45(4); N(2)Pd(1)N(1) 78.12(4) .

The complex 3 reacted with bromine or iodine oxidants to give the corresponding complex 2a or $\mathbf{2 b}$ and 3,3-dimethyl-2,3-dihydro-benzofuran (BF) according to equation (4). Complexes 2a and $\mathbf{2 b}$ were characterized as described above, while the organic product 3,3dimethyl-2,3-dihydro-benzofuran was identified by its NMR and mass spectra, and isolated in $27 \%$ yield from the reaction with iodine. ${ }^{15}$ The reaction is expected to occur by an oxidative addition-reductive elimination sequence, but no palladium(IV) intermediate was detected. The presumed reductive elimination step occurs selectively by $\mathrm{C}\left(\mathrm{sp}^{3}\right)-\mathrm{O}$ bond formation, rather than $\mathrm{C}\left(\mathrm{sp}^{3}\right)-\mathrm{X}$ bond formation. The formation of $\mathbf{2} \mathbf{a} / \mathbf{b}$ and $\mathrm{BF}$ is consistent with halide oxidation of the analogous O-atom inserted nickel complex studied by Hillhouse ${ }^{8}$ (Scheme 3). The reaction of $\mathbf{1}$ with excess hydrogen peroxide occurs to give $\mathbf{3}$ (eq. 3) and then further reaction occurs with release of 3,3-dimethyl-2,3-dihydro-benzofuran (eq. 4). In this case the expected dihydroxopalladium(II) complex $\mathbf{2 c}$ has not been obtained in pure form. When the reaction with $\mathrm{H}_{2} \mathrm{O}_{2}$ was monitored by ${ }^{1} \mathrm{H}$ NMR spectroscopy, imine resonances for a symmetrical complex, 
suggested to be $\mathbf{2 c}$, were observed but they decayed over a period of hours. It is well known that hydroxopalladium(II) complexes tend to form dimers or oligomers by forming bridging hydroxide or oxide groups, and this may occur with the proposed complex $\mathbf{2 c}$. $^{16,17}$ However, we have not been able to isolate pure products or to identify them by NMR spectroscopy or ESI-MS or MALDI-MS, and the characterization of $\mathbf{2 c}$ remains tentative. The requirement for excess hydrogen peroxide in this case suggests that a parallel palladium catalyzed decomposition of hydrogen peroxide may occur. ${ }^{17}$

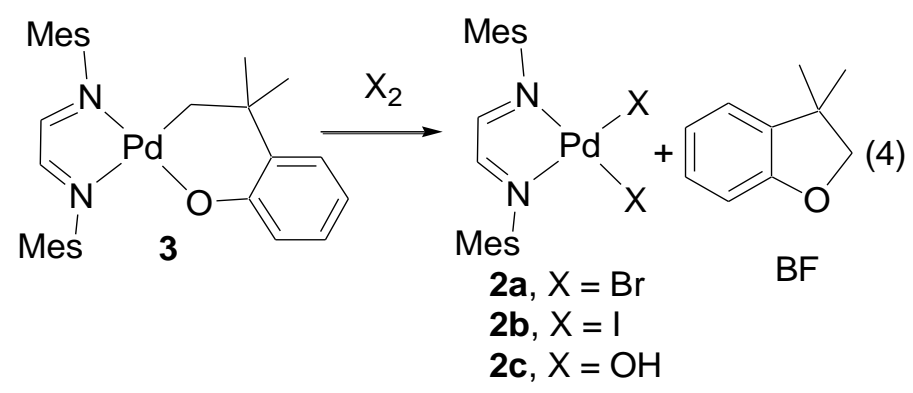

A solution of complex 3 in acetone- $d_{6}$ reacted quickly with $\mathrm{CO}(1 \mathrm{~atm})$ to give a precipitate of palladium black. After 15 minutes, the solution was filtered to remove the $\mathrm{Pd}$ and the organic products were identified as the free diimine ligand and 4,4-dimethyl-2-oxo-2H-1benzopyran (BP) by their ${ }^{1} \mathrm{H}$ NMR spectra (equation 5). The formation of the benzopyran derivative BP was confirmed by GC-MS, and was the only product derived from the palladacycle unit of $\mathbf{3}$ that was detected. In this case, the product is suggested to form by CO insertion followed by reductive elimination from a palladium(II) complex intermediate. The nickel(II) complex $\boldsymbol{J}$ (Scheme 3) gives a similar reaction with carbon monoxide to form BP. ${ }^{8}$

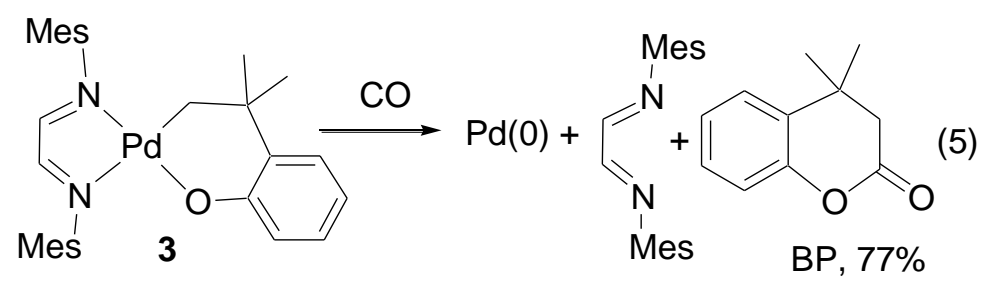

To gain more insight into the selective oxygen atom insertion reaction to give complex $\mathbf{3}$, DFT calculations were carried out (see experimental section for details). Some of the potential reactions of complex 1 with hydrogen peroxide are shown in Scheme 6, and calculations of the energies of reaction were carried out for each case. The simplest reactions considered were trans or cis oxidative addition to give the palladium(IV) complexes 5a, 5b or 5c. More complex reactions involve oxidative addition followed either by reductive elimination with $\mathrm{C}-\mathrm{O}$ bond 
formation to give $\mathbf{3}$ or $\mathbf{4}$ and water or $\mathbf{6}$ or $\mathbf{7}$, or reductive elimination with C-C bond formation to give 2c and 1,1-dimethylcyclobutabenzene, CB. Of the palladium(IV) isomers $\mathbf{5 a}-\mathbf{5 c}$, the product of trans oxidative addition, $\mathbf{5 a}$, is calculated to be most stable and, in related platinum(II) chemistry, trans oxidative addition is also preferred kinetically in the polar mechanism of oxidative addition of O-O bonds. ${ }^{18}$ Formation of complex $\mathbf{3}$ or $\mathbf{4}$ involves overall oxygen atom insertion into the $\mathrm{Pd}-\mathrm{C}\left(\mathrm{sp}^{2}\right)$ or $\mathrm{Pd}-\mathrm{C}\left(\mathrm{sp}^{3}\right)$ bond, respectively, and formation of $\mathbf{3}$ is favoured by $45 \mathrm{~kJ} \mathrm{~mol}^{-1}$ over 4 . Similarly, the complex 6 or 7 would be formed by formal $\mathrm{C}\left(\mathrm{sp}^{2}\right)-\mathrm{O}$ or $\mathrm{C}\left(\mathrm{sp}^{3}\right)-\mathrm{O}$ reductive elimination from $\mathbf{5 a}-\mathbf{5 c}$. Product $\mathbf{6}$ (which is analogous to complex $\boldsymbol{H}$ in Scheme 2) is calculated to be at lower energy than 7 by $45 \mathrm{~kJ} \mathrm{~mol}^{-1}$. The theory thus indicates that the products of aryl-oxygen bond formation, $\mathbf{3}$ or $\mathbf{6}$, which are related by addition or loss of water, are thermodynamically most stable. Simple calculated bond energies favor $\mathbf{6}$ over $\mathbf{3}+$ $\mathrm{H}_{2} \mathrm{O}$ by $9 \mathrm{~kJ} \mathrm{~mol}^{-1}$ but, if the water remains hydrogen bonded to $\mathbf{3}$, then $\mathbf{3} \cdot \mathrm{H}_{2} \mathrm{O}$ is more stable than 6 by $41 \mathrm{~kJ} \mathrm{~mol}^{-1}$. Of course, entropy effects favor $3+\mathrm{H}_{2} \mathrm{O}$ over $\mathbf{6}$. The products will, of course, be controlled by kinetic factors but the selective formation of complex $\mathbf{3}$ (Scheme 6) is consistent with there being a lower activation energy for formation of a more stable product. 


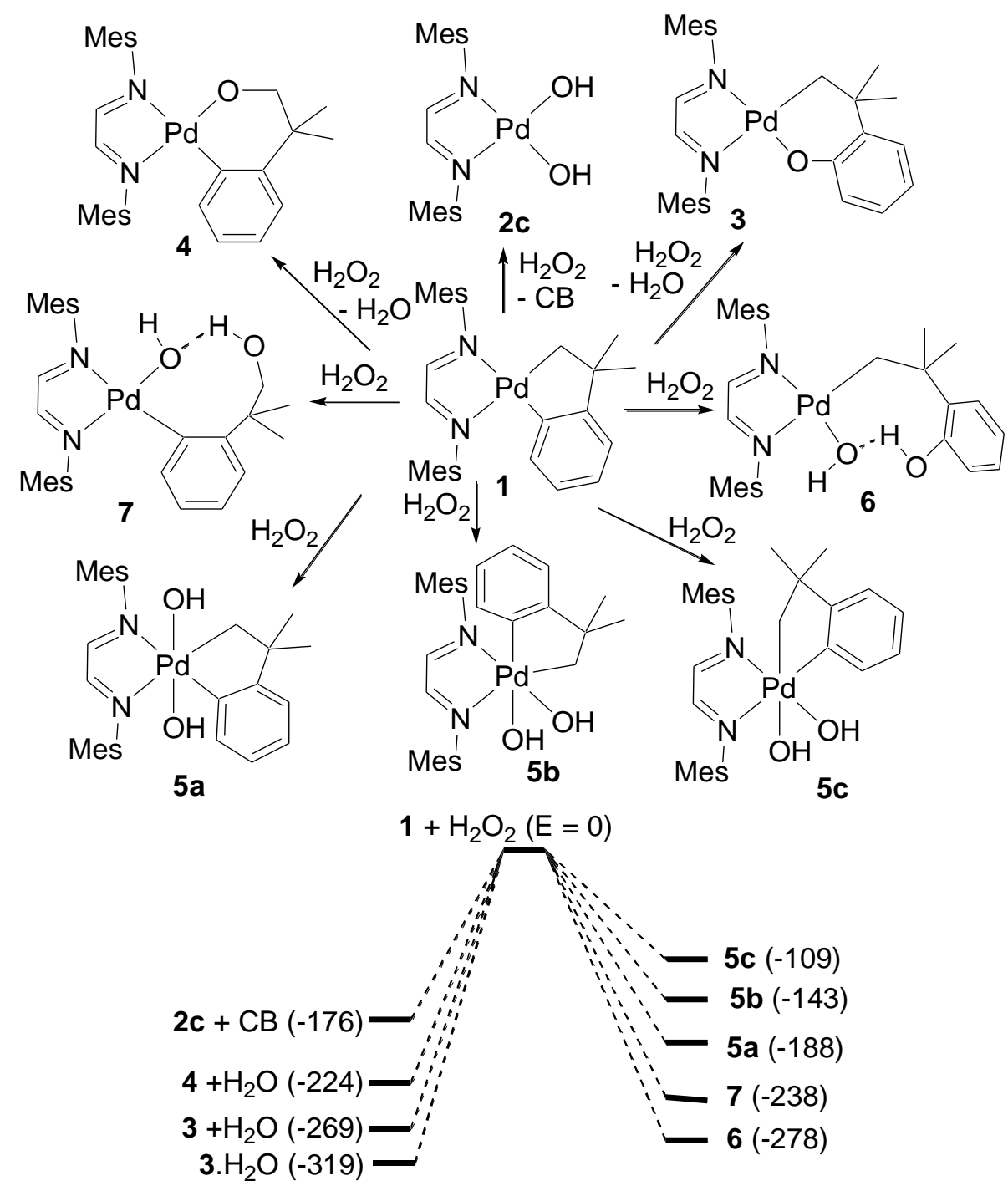

Scheme 6. Above, some potential reactions of complex 1 with $\mathrm{H}_{2} \mathrm{O}_{2}$ and, below, the calculated energies of reaction in $\mathrm{kJ} \mathrm{mol}^{-1}$.

A suggested mechanism of reaction to give complex 3 is shown in Figure 5. An initial encounter complex $\mathbf{8}$ is formed between complex $\mathbf{1}$ and $\mathrm{H}_{2} \mathrm{O}_{2}$, involving donation from the filled $4 \mathrm{~d}_{\mathrm{z}} 2$ orbital of 1 to the vacant $\sigma^{*}(\mathrm{OO})$ orbital of $\mathrm{H}_{2} \mathrm{O}_{2}$, indicated by $\boldsymbol{M}$ in Fig. 5, leading to an increase in the calculated $\mathrm{O}-\mathrm{O}$ bond distance from $1.59 \AA$ to $1.72 \AA$. The rate determining step is likely to involve further charge transfer to $\mathrm{H}_{2} \mathrm{O}_{2}$ with cleavage of the O-O bond to give the proposed palladium(IV) complex intermediate 9. Complex 9 can be considered to contain a $\mathrm{Pd}^{+} \mathrm{OH}$ group hydrogen bonded to hydroxide or an oxopalladium $\left(\mathrm{Pd}^{+} \mathrm{O}^{-}\right)$group hydrogen bonded to water. The importance of such an intermediate is consistent with the experimental 
observation that polar solvents are preferable for this reaction. Since the reagent used was $30 \%$ aqueous $\mathrm{H}_{2} \mathrm{O}_{2}$, it is likely that additional water molecules may be involved in stabilizing $\mathbf{9}$, and so its structure is tentative. ${ }^{19}$ With this proviso, the calculation suggests that it should be considered primarily as an oxo complex, with the significant hydrogen bonding to water (Figure 5) providing a mechanism to avoid the "oxo wall". ${ }^{10,20}$ Once C-O bond formation begins, the formation of complex 10, which is just complex $\mathbf{3}$ hydrogen bonded to water, is very favorable, and then dissociation of water gives the observed product 3 . The mechanism (Figure 5) can be considered to combine the deprotonation and bond formation steps of the proposed Mirica mechanism ${ }^{5}$ of Scheme 2. Generation of $\mathbf{3}$ via the latter, stepwise, path cannot be conclusively discarded. In such a process, complex $\mathbf{1 0}$ could be considered to be an intermediate on the way to a phenol derivative along with hydroxide, and this step could be followed by deprotonation of the phenol to give 3. Deprotonation would be disfavoured in the Mirica system since such a step would generate the strong acid $\mathrm{HClO}_{4}$ rather than the equivalent of $\mathrm{H}_{2} \mathrm{O}$ produced here.

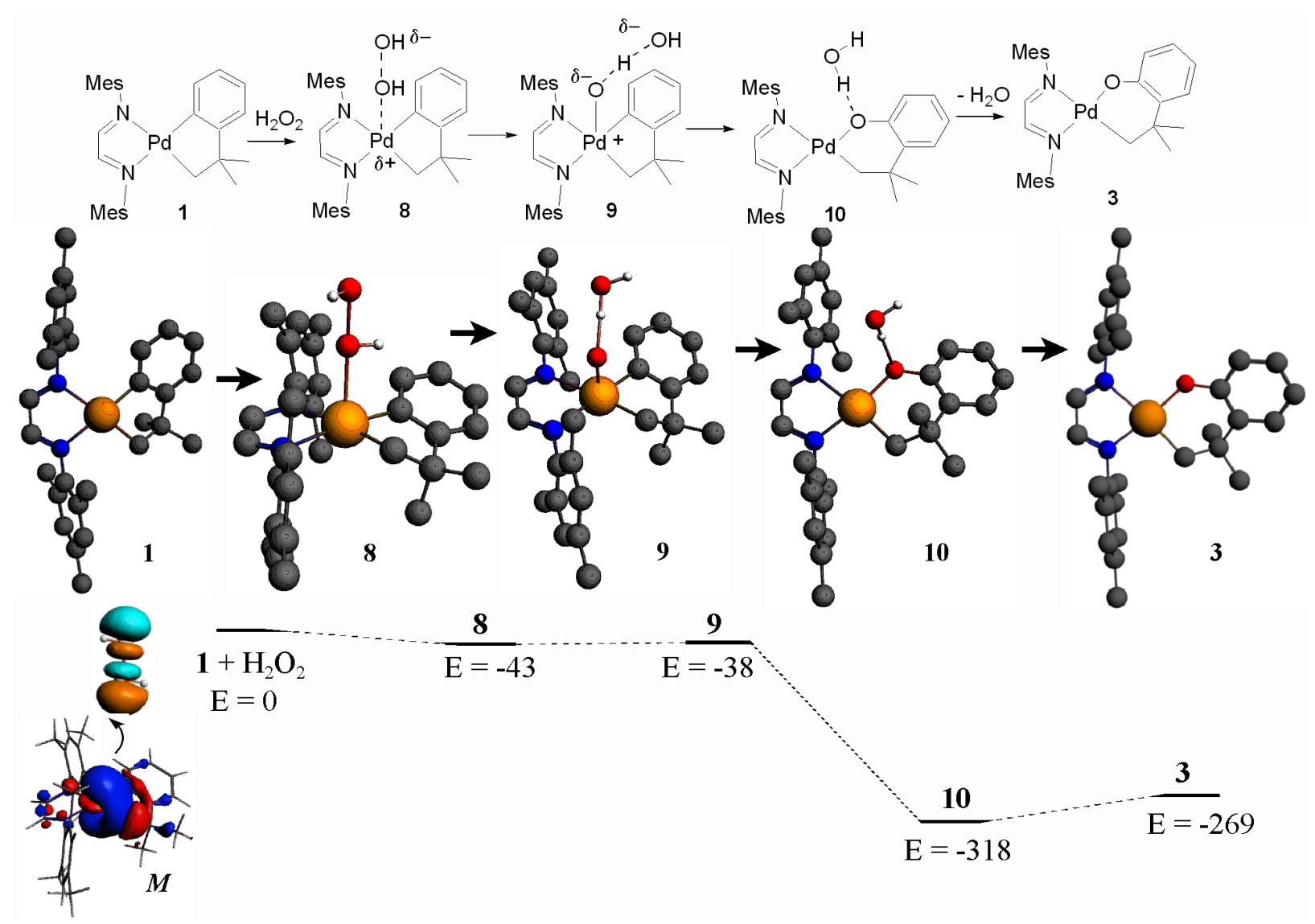


Figure 5. Calculated structures and relative energies $\left(\mathrm{kJ} \mathrm{mol}^{-1}\right)$ of complexes and intermediates in the reaction of $\mathbf{1}$ with $\mathrm{H}_{2} \mathrm{O}_{2}$ to give complex 3. I represents the proposed initial interaction between the $4 \mathrm{~d}_{\mathrm{z}} 2 \mathrm{HOMO}$ of complex 1 and the $\sigma^{*} \mathrm{LUMO}$ of $\mathrm{H}_{2} \mathrm{O}_{2}$. Selected calculated bond parameters: $\mathrm{H}_{2} \mathrm{O}_{2}$, O-O 1.59, O-H 1.01 A; 6, Pd $\mathrm{OO}$ 2.47, O-O 1.72, PdO-H 1.00, PdOO-H 1.01

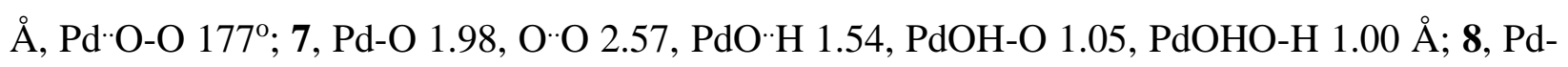
O 2.02, O O 2.77, PdO $*$ H 1.77, PdOH-O 1.01, PdOHO-H 0.99 Å; 3, Pd-O $2.02 \AA$.

Scheme 6 shows the potential products and their relative energies from reaction of complex 1 with bromine and iodine. In this case the reaction to give 2a and 1,1dimethylcyclobutabenzene (CB) is calculated to be most favorable, again consistent with the experimental observations. The preference for $\mathrm{C}-\mathrm{C}$ over $\mathrm{C}-\mathrm{X}$ reductive elimination is calculated to follow the sequence $\mathrm{X}=\mathrm{I}>\mathrm{Br}>\mathrm{OH}$ (Schemes 6 and 7) and can be rationalized by the relative $\mathrm{Pd}-\mathrm{X}$ and $\mathrm{C}-\mathrm{X}$ bond dissociation energies, with $\mathrm{D}(\mathrm{C}-\mathrm{X})-\mathrm{D}(\mathrm{Pd}-\mathrm{X})$ following the ligand hardness sequence $X=\mathrm{OH}>\mathrm{Br}>\mathrm{I}$. In contrast to the case with $\mathrm{X}=\mathrm{OH}$ (Scheme 6), the theory predicts that for $\mathrm{C}-\mathrm{X}$ bond formation, reaction at $\mathrm{C}\left(\mathrm{sp}^{3}\right)$ is preferred over $\mathrm{C}\left(\mathrm{sp}^{2}\right)$, with $\mathbf{1 1}$ being lower in energy than 12 (Scheme 7). 


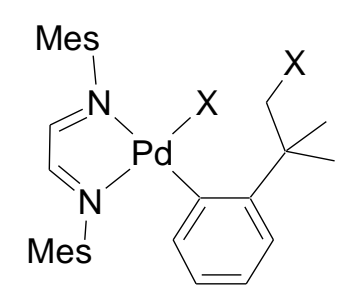

11a, $X=\mathrm{Br}$

11b, $X=I$<smiles></smiles><smiles>[X]C1([Y])CC(C)(C)c2ccccc21</smiles>

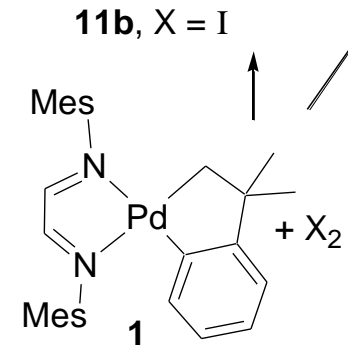

12a, $X=B r$

$12 b, X=I$

13a, $X=\mathrm{Br}$

$13 b, X=I$
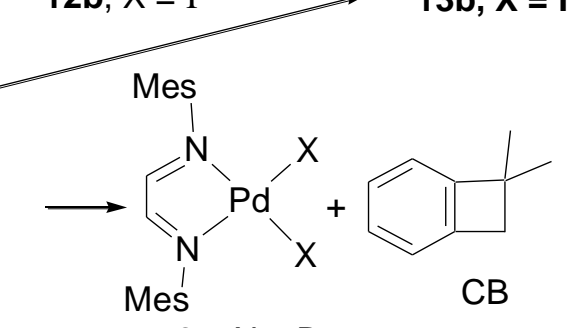

2a, $\mathrm{X}=\mathrm{Br}$

2b, $X=I$

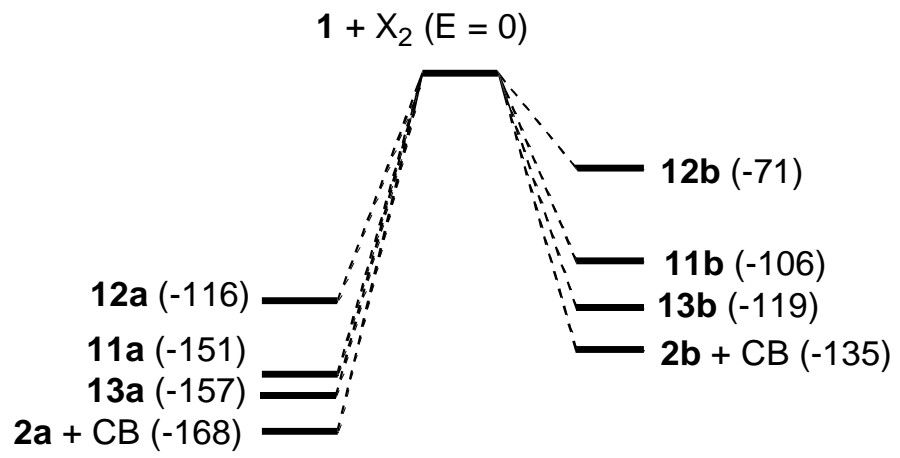

Scheme 7. Some possible products, and their relative energies $\left(\mathrm{kJ} \mathrm{mol}^{-1}\right)$ from reaction of complex 1 with bromine or iodine.

In the above examples, the thermodynamically more stable products are also favored kinetically as they are the experimentally observed products. This is also the case for the reactions of 3 with $\mathrm{Br}_{2}$ and $\mathrm{I}_{2}$ (Scheme 8). The calculations show that oxidation followed by intramolecular $\mathrm{C}\left(\mathrm{sp}^{3}\right)-\mathrm{O}$ reductive elimination to give $\mathrm{BF}$ and $\mathbf{2} \mathbf{a} / \mathbf{b}$ is more favourable than reductive elimination to give $\mathbf{1 5 a} / \mathbf{b}$ that contains a new $\mathrm{C}\left(\mathrm{sp}^{3}\right)-\mathrm{X}$ bond $(\mathrm{X}=\mathrm{Br}$, I). In contrast, $\mathbf{2 c}$ and $\mathrm{BF}$ are not the most favourable products for oxidation of $\mathbf{3}$ with $\mathrm{H}_{2} \mathrm{O}_{2}$. Instead, the more stable product is expected to be $\mathbf{1 5 c}$ or the cyclic derivative 16. Experimentally BF is observed as a product of oxidation of $\mathbf{3}$ with $\mathrm{H}_{2} \mathrm{O}_{2}$ (eq. 4). It is expected that the products in all of the reactions are determined by kinetic control and this is the only case in which the product is not also the most thermodynamically stable, as calculated by DFT. 


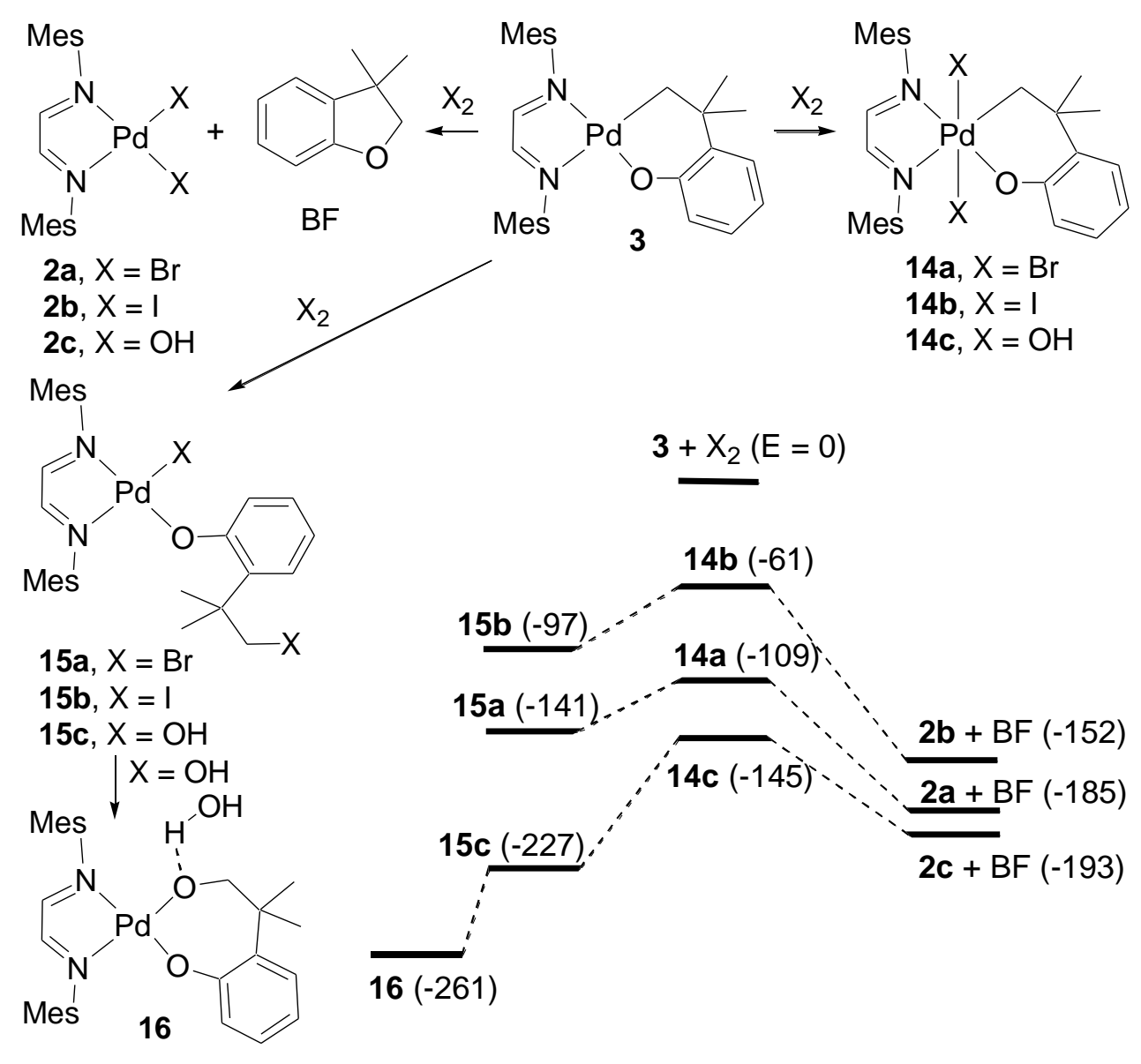

Scheme 8. Potential products, and their relative energies from reactions of complex 3.

From a mechanistic point of view, the reductive elimination following oxidation of $\mathbf{3}$ with $\mathrm{Br}_{2}, \mathrm{I}_{2}$ or $\mathrm{H}_{2} \mathrm{O}_{2}$ is likely to occur from a 5-coordinate $\mathrm{Pd}(\mathrm{IV})$ intermediate (Scheme 9 for the representative example with $\mathrm{I}_{2}$ ). Initial attack by the electrophilic iodine is likely to give the diiodine complex 12, for which several precedents are known. ${ }^{21}$ Complete I-I bond cleavage from 12 followed by attack of the iodide ion at palladium or at the $\mathrm{CH}_{2}$ group would give $\mathbf{9 b}$ or $\mathbf{1 0 b}$ respectively (Scheme 8). However, intramolecular C-O reductive elimination to give $\mathbf{2 b}$ is evidently preferred, perhaps after pseudorotation of $\mathbf{1 2}$ to give the isomer $\mathbf{1 3}$ so that the initial benzofuran (BF) palladium(II) complex $\mathbf{1 5}$ is formed in its most stable form by way of transition state 14. Then displacement of BF by iodide via complex 16 completes the reaction. 


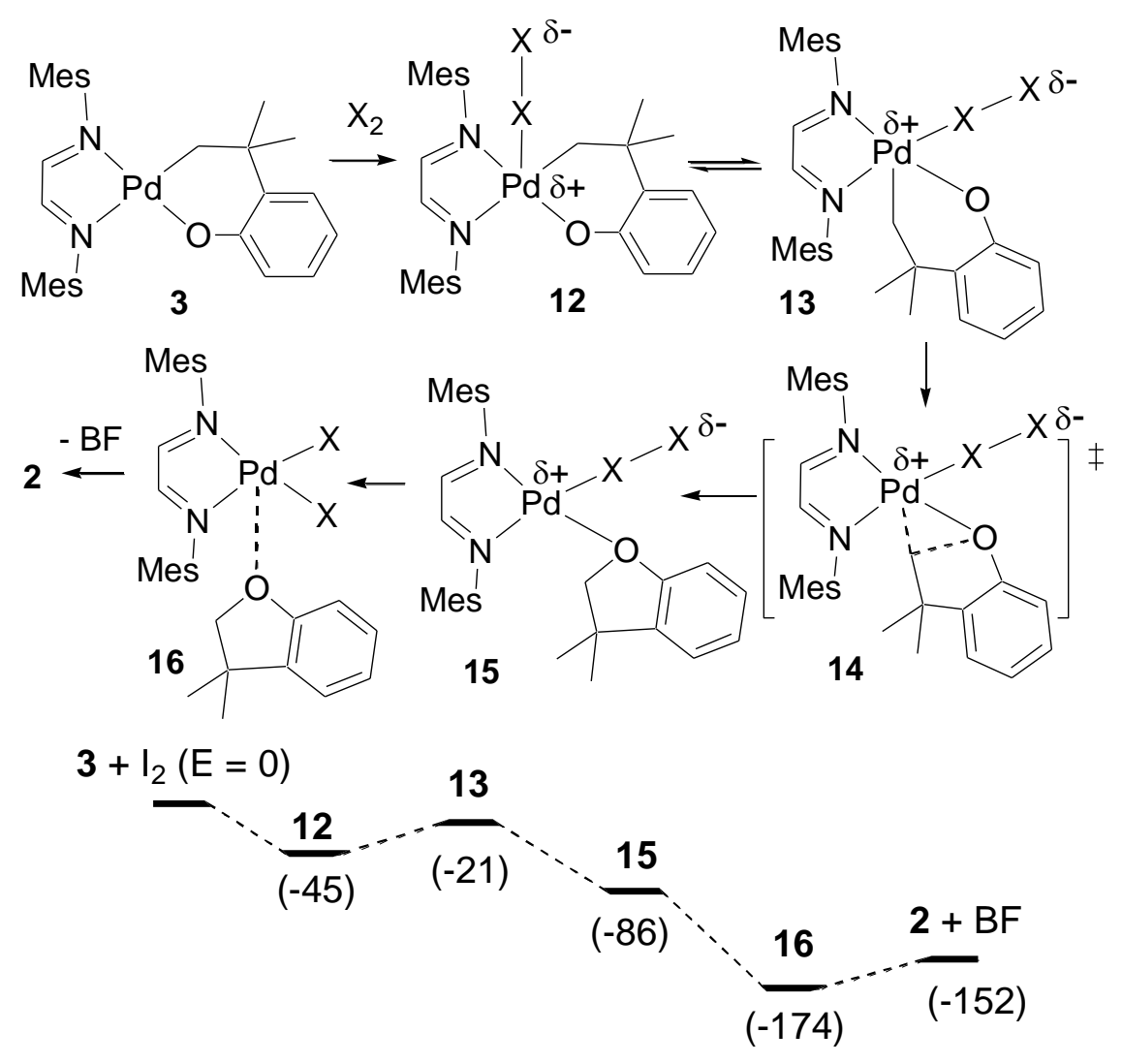

Scheme 9. A likely mechanism for reactions of complex 3 with oxidants $\mathrm{X}_{2}(\mathrm{X}=\mathrm{Br}, \mathrm{I}, \mathrm{OH})$, and the relative energies $\left(\mathrm{kJ} \mathrm{mol}^{-1}\right)$ for the case with $\mathrm{X}=\mathrm{I}$.

\section{Conclusions}

The initial reaction of complex 1 with hydrogen peroxide occurs to give selective oxygen atom insertion into the arylpalladium bond to give complex 3 (eq. 3), while the reactions with bromine and iodine lead to intramolecular $\mathrm{C}-\mathrm{C}$ bond formation to give 1,1dimethylcyclobutabenzene and $\mathbf{2 a}$ or $\mathbf{2 b}$ (eq. 2). Complex $\mathbf{3}$ reacts with all three oxidants by intramolecular C-O bond formation to give 3,3-dimethyl-2,3-dihydro-benzofuran and $\mathbf{2 a}, \mathbf{2 b}$ or 2c (eq. 4). In most cases, experimentally observed oxidation products were calculated to be the most thermodynamically stable products. This suggests that, in similar systems, thermodynamic stability can act as a good guide for kinetically controlled oxidation selectivity. The observed oxygen atom insertion may be an operative process in $\mathrm{C}-\mathrm{O}$ bond forming reactions catalyzed by $\mathrm{Pd}$ with $\mathrm{H}_{2} \mathrm{O}_{2}$ as the oxidant. The selectivity observed here is promising for a greater development in catalytic oxidations of hydrocarbons. 


\section{Experimental}

Reagents and general procedures. All reactions were carried out under air, unless otherwise specified. For those reactions that were conducted under nitrogen atmosphere, standard Schlenk techniques were used. All solvents used for air- and moisture-sensitive reactions were purified using an Innovative Technologies 400-5 Solvent Purification System (SPS) and were stored over activated $4 \AA$ molecular sieves. NMR spectra were recorded at $298 \mathrm{~K}$ using Varian INOVA 400 or $600 \mathrm{MHz}$ spectrometers. ${ }^{1} \mathrm{H}$ and ${ }^{13} \mathrm{C}$ chemical shifts were referenced internally to solvent (residual signal for ${ }^{1} \mathrm{H}$ ) where the chemical shift was set to appropriate values relative to TMS at $0.00 \mathrm{ppm}$. Complete assignment of each compound was aided by the use of ${ }^{1} \mathrm{H}-{ }^{1} \mathrm{H}$ gCOSY, ${ }^{1} \mathrm{H}-{ }^{13} \mathrm{C}\left\{{ }^{1} \mathrm{H}\right\}$ HSQC and ${ }^{1} \mathrm{H}-{ }^{13} \mathrm{C}\left\{{ }^{1} \mathrm{H}\right\}$ HMBC experiments, and are reported using the labeling scheme in Chart 1. Commercial reagents and aqueous $30 \% \mathrm{H}_{2} \mathrm{O}_{2}$ were used without further purification. The complex $\left[\mathrm{PdCl}_{2}(\mathrm{COD})\right]^{5,6 \mathrm{a}}$, and the diimine ligand, 1,2bis(mesitylimino)ethane, ${ }^{12}$ were synthesized according to the literature procedures. The complex $\left[\mathrm{PdCl}\left(\mathrm{CH}_{2} \mathrm{CMe}_{2} \mathrm{C}_{6} \mathrm{H}_{5}\right)(\mathrm{COD})\right]^{5,6 \mathrm{a}}$ was prepared under $\mathrm{N}_{2}$ following the procedure reported by Mirica et $a l .{ }^{5}$ with the following slight modification: after addition of the Grignard reagent at $70^{\circ} \mathrm{C}$, the solution was stirred at low temperature and allowed to slowly reach room temperature over $17 \mathrm{~h}$. Complex $\left[\mathrm{Pd}\left(\mathrm{CH}_{2} \mathrm{CMe}_{2} \mathrm{C}_{6} \mathrm{H}_{4}\right)(\mathrm{COD})\right]^{5,6 \mathrm{a}}$ was also prepared under $\mathrm{N}_{2}$ following a procedure from Mirica et. al. ${ }^{5}$ with the following minor modification: the reaction was carried out using an ice bath, and a degassed water solution was used to dissolve the base. In both modified syntheses, ${ }^{1} \mathrm{H}$ NMR spectra matched literature values and yields were improved by $30 \%$ and $10 \%$, respectively. Elemental analyses were performed by Laboratoire d'Analyze Élémentaire de l'Université de Montréal. Organic products were analyzed using a Shimadzu GCMS-QP2010 Ultra GC with a DB-5 column. MALDI-TOF mass spectra were collected using an AB Sciex 5800 TOF/TOF mass spectrometer using anthracene as the matrix in a 20:1 matrix:substrate molar ratio. 


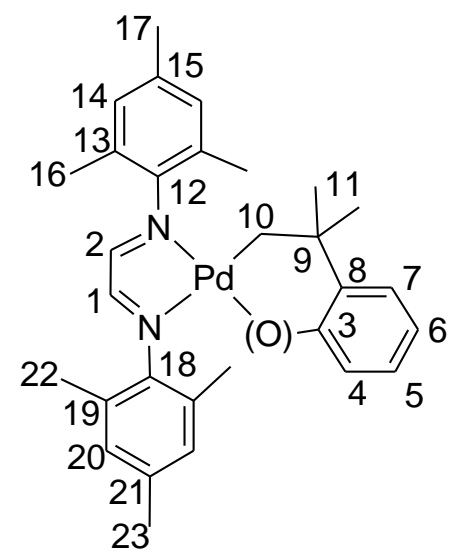

Chart 1. Atom labels for complexes $\mathbf{1}$ and $\mathbf{2}$ for NMR spectroscopy assignments

$\left[\mathrm{Pd}^{\mathrm{II}}\left(\mathrm{CH}_{2} \mathrm{CMe}_{2} \mathrm{C}_{6} \mathrm{H}_{4}\right)(\mathrm{MesN}=\mathrm{CH}-\mathrm{CH}=\mathrm{NMes})\right]$, 1 . To a stirred solution of $\left[\mathrm{Pd}\left(\mathrm{CH}_{2} \mathrm{CMe}_{2} \mathrm{C}_{6} \mathrm{H}_{4}\right)(\mathrm{COD})\right]\left(0.907 \mathrm{~g}, 2.00 \mathrm{mmol}\right.$ in ether $(50 \mathrm{~mL})$ cooled to $-65^{\circ} \mathrm{C}$ was added a solution of MesN=CH-CH=NMes $(0.764 \mathrm{~g}, 2.00 \mathrm{mmol})$ in ether $(20 \mathrm{~mL})$. The mixture was allowed to stir and slowly reach room temperature over $17 \mathrm{~h}$, during which time the color of the solution changed from yellow to red. Upon removal of the solvent under reduced pressure, a red solid was formed, which was reprecipitated from ether $(5 \mathrm{~mL})$ with hexanes $(30 \mathrm{~mL})$. The solid was collected by filtration and dried under vacuum, to give $\mathbf{1}$ as an air-stable product $(0.841 \mathrm{~g}$, $1.58 \mathrm{mmol}, 75 \%)$. ${ }^{1} \mathrm{H}$ NMR $\left(\mathrm{C}_{6} \mathrm{D}_{6}, 600 \mathrm{MHz}\right): \delta 7.06(\mathrm{~s}, H 1,1 \mathrm{H}), 7.05(\mathrm{~s}, H 2,1 \mathrm{H}), 7.00(\mathrm{t}, J=$ $7 \mathrm{~Hz}, H 5,1 \mathrm{H}), 6.94(\mathrm{~d}, J=7 \mathrm{~Hz}, H 4,1 \mathrm{H}), 6.86(\mathrm{~m}, H 6,1 \mathrm{H}), 6.77$ (s, H20, 2H), 6.75 (s, H14, 2H), 6.65 (d, $J=8 \mathrm{~Hz}, H 7,1 \mathrm{H}), 2.48$ (s, H10, 2H), 2.17 (s, H16 and H17, 9H), 2.12 (s, H22, $6 \mathrm{H}), 2.10(\mathrm{~s}, H 23,3 \mathrm{H}), 1.49\left(\mathrm{~s}, H 11,6 \mathrm{H},{ }^{13} \mathrm{C} \mathrm{NMR}\left(\mathrm{C}_{6} \mathrm{D}_{6}, 600 \mathrm{MHz}\right): \delta 170.19(C 8), 161.64\right.$ (C1), 161.45 (C2), 158.71 (C3), 147.44 (C18), 146.66 (C12), 136.36 (C15), 136.26 (C21), 134.85 (C7), 129.61 (C14), 129.47 (C20), 128.93 (C13 and C19), 124.76 (C5), 124.40 (C6), 122.61 (C4), 48.00 (C9), 47.58 (C10), 34.68 (C11), 21.40 (C23), 21.32 (C17), 18.85 (C22), 18.45 ( $C 16)$. Note that the correlations do not identify specific rings, so assignments for the C12$\mathrm{C} 17$ and $\mathrm{C} 18-\mathrm{C} 23$ rings, and for imine groups $\mathrm{C} 1$ and $\mathrm{C} 2$, are arbitrary and could be inverted. MALDI MS (anthracene matrix): Calc. $m / z \quad 530.2 \quad[\mathrm{Pd}(\mathrm{MesN}=\mathrm{CH}-$ $\left.\mathrm{CH}=\mathrm{NMes})\left(\mathrm{CH}_{2} \mathrm{CMe}_{2} \mathrm{C}_{6} \mathrm{H}_{4}\right)\right]^{\bullet+}$, Obs. $\mathrm{m} / z$ 530.2. Anal. Calc for $\mathrm{C}_{30} \mathrm{H}_{36} \mathrm{~N}_{2} \mathrm{Pd}: \mathrm{C}, 67.85 ; \mathrm{H}, 6.83$; N, 5.28. Found: C, 67.81; H, 7.00; N, 5.14. Red crystals suitable for single crystal X-ray crystallographic analysis were grown by the slow evaporation of a solution of $\mathbf{1}$ in ether at room temperature. 
[PdBr2(MesN=CH-CH=NMes)], 2a: To a solution of complex $1(0.020 \mathrm{~g}, 0.037 \mathrm{mmol})$ in acetone $(2 \mathrm{~mL})$ was added excess $\mathrm{Br}_{2}(10.4 \mu \mathrm{L}, 0.203 \mathrm{mmol})$ whilst stirring. After 5 min the reaction mixture became a bright orange color. After $2 \mathrm{~h}$ the volume of solvent was reduced to $\sim 1 \mathrm{~mL}$ and pentane $(4 \mathrm{~mL})$ was added to precipitate the product as an orange powder, which was separated by filtration, washed with pentane $(3 \times 2 \mathrm{~mL})$ and hexanes $(3 \times 2 \mathrm{~mL})$, and dried under high vacuum $(0.021 \mathrm{~g}, 0.031 \mathrm{mmol}, 85 \%) .{ }^{1} \mathrm{H}$ NMR (600 MHz, DMSO- $\left.d_{6}\right) \delta: 8.27$ (s, $2 \mathrm{H}$, $\mathrm{C} H=\mathrm{N}$ ), 6.97 (s, $4 \mathrm{H}$, mes- $H$ ), 2.29 (s, $18 \mathrm{H}, 6 \mathrm{Me}$ ). Anal. Calc for $\mathrm{C}_{20} \mathrm{H}_{24} \mathrm{Br}_{2} \mathrm{~N}_{2} \mathrm{Pd}: \mathrm{C}, 43.00 ; \mathrm{H}$, 4.33; N, 5.01. Found: C, 43.35; H, 4.42; N, 4.85. Orange crystals suitable for single crystal X-ray crystallographic analysis were grown from the slow vapor diffusion of methanol into a DMSO solution of $\mathbf{2 a}$.

[PdI $\left.\mathbf{P}_{2}(\mathbf{M e s N}=\mathbf{C H}-\mathbf{C H}=\mathbf{N M e s})\right], \mathbf{2 b}$. Compound $\mathbf{2 b}$ was synthesized in a similar way to $\mathbf{2 a}$, but using $\mathrm{I}_{2}\left(0.027 \mathrm{~g}, 0.092 \mathrm{mmol}, 2.5\right.$ equiv) instead of $\mathrm{Br}_{2}$. The dark red solid was formed in $65 \%$ yield $(0.028 \mathrm{~g}, 0.036 \mathrm{mmol}){ }^{1} \mathrm{H}$ NMR $\left(600 \mathrm{MHz},\left(\mathrm{CD}_{3}\right)_{2} \mathrm{CO}\right) \delta: 8.51(\mathrm{~s}, 2 \mathrm{H}, \mathrm{CH}=\mathrm{N}), 6.95(\mathrm{~s}$, $4 \mathrm{H}$, mes- $H$ ), 2.30 (m, $18 \mathrm{H}, 6 \mathrm{Me}$ ). Anal. Calc for $\mathrm{C}_{20} \mathrm{H}_{24} \mathrm{I}_{2} \mathrm{~N}_{2} \mathrm{Pd}: \mathrm{C}, 36.81 ; \mathrm{H}, 3.71$. Found: $\mathrm{C}$, 36.90; $\mathrm{H}, 3.71$. Orange crystals suitable for single crystal $\mathrm{X}$-ray crystallographic analysis were grown by the slow evaporation of acetone solution of $\mathbf{2} \mathbf{b}$ in the room temperature.

$\left[\mathrm{Pd}(\mathrm{MesN}=\mathrm{CH}-\mathrm{CH}=\mathrm{NMes})\left(\mathrm{CH}_{2} \mathrm{CMe}_{2} \mathrm{C}_{6} \mathrm{H}_{4} \mathrm{O}\right)\right]$, 3. A vial was charged with a stir bar, 1 (0.040 $\mathrm{g}, 0.072 \mathrm{mmol}$ ) and acetone ( $4 \mathrm{~mL}$ ). The $\mathrm{H}_{2} \mathrm{O}_{2}$ solution ( $7.5 \mu \mathrm{L}, 2$ equiv, $0.14 \mathrm{mmol}$ ) was added to the vial via a microliter syringe while stirring. The solution was stirred for $3 \mathrm{~h}$. and then the solvent was evaporated to dryness and residue was washed with hexanes $(3 \times 3 \mathrm{~mL})$. The crude product was isolated by silica gel column chromatography (9:1 ethyl acetate:pentane) $\left(\mathrm{R}_{\mathrm{f}}=\right.$ 0.087). The product was observed as a dark green band and fractions of this colour were combined and the solvent was removed under vacuum to give $\mathbf{3}$ as a dark-green solid in 50\% yield $(0.019 \mathrm{mg}, 0.036 \mathrm{mmol}) .{ }^{1} \mathrm{H} \mathrm{NMR}\left(\left(\mathrm{CD}_{3}\right)_{2} \mathrm{CO}, 600 \mathrm{MHz}\right): \delta\left({ }^{1} \mathrm{H}\right)=8.57(\mathrm{~s}, H 1,1 \mathrm{H}), 8.44(\mathrm{~s}$, $H 2,1 \mathrm{H}), 7.01$ (s, H14, 2H), 6.98 (s, H20, 2H), 6.78 (d, 1H, $J=8 \mathrm{~Hz}, H 4), 6.63$ (m, 1H, H5), 6.25 $(\mathrm{d}, 1 \mathrm{H}, J=8 \mathrm{~Hz}, H 7), 6.19$ (t, $J=8 \mathrm{~Hz}, H 6,1 \mathrm{H}), 2.38$ (s, $H 22,6 \mathrm{H}), 2.32(\mathrm{~s}, H 17,3 \mathrm{H}), 2.32$ (s, $H 23,3 \mathrm{H}), 2.25$ (s, H16, 6H), $1.73(\mathrm{~s}, H 10,2 \mathrm{H}), 1.10(\mathrm{~s}, H 11,6 \mathrm{H}) ; \delta\left({ }^{13} \mathrm{C}\right)=167.14(C 1), 164.40$ (C3), 162.85 (C2), 145.26 (C12), 145.09 (C18), 138.85 (C8), 136.85 (C21), 136.30 (C15), 129.54 (C19), 129.38 (C13), 129.25 (C20), 129.11 (C14), 126.12 (C5), 124.89 (C4), 118.98 (C7), 113.44 (C6), 47.58 (C10), 34.50 (C9), 30.84 (C11), 20.76 (C23), 20.69 (C17), 18.39 (C22), 
17.67 ( $C 16)$. Note that the correlations do not identify specific rings, so assignments for the C12$\mathrm{C} 17$ and $\mathrm{C} 18-\mathrm{C} 23$ rings, and for imine groups $\mathrm{C} 1$ and $\mathrm{C} 2$, are arbitrary and could be inverted. MALDI MS (Anthracene matrix): Calc. $\mathrm{m} / \mathrm{z} 546.2 \quad[\mathrm{Pd}(\mathrm{MesN}=\mathrm{CH}-$ $\left.\mathrm{CH}=\mathrm{NMes})\left(\mathrm{CH}_{2} \mathrm{CMe}_{2} \mathrm{OC}_{6} \mathrm{H}_{4}\right)\right]^{\bullet+}$, Obs. $m / z$ 546.2. Anal. Calc for $\mathrm{C}_{30} \mathrm{H}_{36} \mathrm{~N}_{2} \mathrm{OPd} . \mathrm{H}_{2} \mathrm{O}: \mathrm{C}, 63.77$; H, 6.78; N, 4.96. Found: C, 64.03; H, 6.67; N, 4.79. Single crystals suitable for X-ray crystallographic analysis were grown by the slow evaporation of a benzene solution of $\mathbf{3}$ at room temperature.

Reaction of complex 1 with halogens. A 1:1 solution of iodine and complex 1 in $\mathrm{CDCl}_{3}$ was monitored by ${ }^{1} \mathrm{H}$ NMR spectroscopy. The resonances for complex $\mathbf{2 b}$ and 1,1-dimethyl-1,2dihydrocyclobutabenzene were observed and complex 1 was completely consumed. ${ }^{4 b, 14}$ After 2 h., the volume of solution was reduced and pentane was added to precipitate complex $\mathbf{2} \mathbf{b}$. The solid was filtered, washed with pentane, and the solvent was removed from the filtrate to give 1,1-dimethyl-1,2-dihydrocyclobutabenzene $\mathrm{CB}$ as a yellow oil, which was redissolved in $\mathrm{CDCl}_{3}$ and characterized by ${ }^{1} \mathrm{H}$ NMR spectroscopy and GC-MS. Yield of CB 37\%, calculated using dimethyl terephthalate as internal standard. ${ }^{1} \mathrm{H}$ NMR for $\mathrm{CB}\left(\mathrm{CDCl}_{3}, 600 \mathrm{MHz}\right): \quad \delta\left({ }^{1} \mathrm{H}\right)=8.01$ (m, 1H, $\left.\mathrm{C}_{6} \mathrm{H}_{4}\right), 7.17\left(\mathrm{~m}, 1 \mathrm{H}, \mathrm{C}_{6} \mathrm{H}_{4}\right), 7.07\left(\mathrm{~m}, 1 \mathrm{H}, \mathrm{C}_{6} \mathrm{H}_{4}\right), 7.01\left(\mathrm{~m}, 1 \mathrm{H}, \mathrm{C}_{6} \mathrm{H}_{4}\right), 2.95\left(\mathrm{~s}, 2 \mathrm{H}, \mathrm{CH}_{2}\right)$, 1.42 (s, $6 \mathrm{H}, \mathrm{Me}$ ). LR-MS: Found: $\mathrm{m} / \mathrm{z}=132.15$. Calc. for $\mathrm{C}_{10} \mathrm{H}_{12}: \mathrm{m} / \mathrm{z}=132.2$. The reaction of 1 with bromine was carried out in a similar way.

Reaction of complex 3 with halogens. A solution of $\mathbf{3}(0.020 \mathrm{~g}, 0.036 \mathrm{mmol})$ and the internal standard dimethyl terephthalate $(0.001 \mathrm{~g}, 0.009 \mathrm{mmol})$ was prepared in acetone- $d_{6}(0.7 \mathrm{~mL})$. A ${ }^{1} \mathrm{H}$ NMR spectrum was obtained to determine the initial ratio of $\mathbf{3}$ to the internal standard. To this was added a solution of iodine $(0.009 \mathrm{~g}, 0.036 \mathrm{mmol})$ in acetone- $d_{6}(0.7 \mathrm{~mL})$ and the reaction was monitored by ${ }^{1} \mathrm{H}$ NMR spectroscopy. The resonances for complex $\mathbf{2} \mathbf{b}$ and 3,3-dimethyl-2,3dihydro-benzofuran, BF, were observed; complex 3 was completely consumed after $2 \mathrm{~h}^{15}$ The in situ yield of BF was calculated to be $27 \%$ relative to the internal standard. Pentane ( $2 \mathrm{~mL}$ ) was added to the reaction solution to precipitate complex $\mathbf{2} \mathbf{b}$. The mixture was filtered, and the filtrate was evaporated to give a crude sample of 3,3-dimethyl-2,3-dihydro-benzofuran, BF, as a pale brown oil. The oil was dissolved in $\mathrm{CDCl}_{3}$ and characterized by ${ }^{1} \mathrm{H}$ NMR spectroscopy and GC-MS. ${ }^{1} \mathrm{H}$ NMR $\left(\mathrm{CDCl}_{3}, 600 \mathrm{MHz}\right): \quad \delta\left({ }^{1} \mathrm{H}\right)=4.22\left(\mathrm{~s}, 2 \mathrm{H}, \mathrm{OCH}_{2}\right), 1.33(\mathrm{~s}, 6 \mathrm{H}, \mathrm{Me})$, in agreement with the literature values. ${ }^{15 a}$ The aromatic signals are obscured due to the presence of 
other signals there. The sample was dissolved in acetone- $d_{6}$ to facilitate identification of BF in other reactions. NMR for $\mathrm{BF}\left(\left(\mathrm{CD}_{3}\right)_{2} \mathrm{CO}, 600 \mathrm{MHz}\right): \delta\left({ }^{1} \mathrm{H}\right)=6.64-6.66\left(\mathrm{~m}, 4 \mathrm{H}, \mathrm{C}_{6} \mathrm{H}_{4}\right), 4.19(\mathrm{~s}$, $\left.2 \mathrm{H}, \mathrm{OCH}_{2}\right), 1.31(\mathrm{~s}, 6 \mathrm{H}, \mathrm{Me})$. GC-MS for BF, Found: $\mathrm{m} / \mathrm{z}=148.2$. Calc. for $\mathrm{C}_{10} \mathrm{H}_{12} \mathrm{O}: \mathrm{m} / \mathrm{z}=$ 148.1. The reaction with bromine was carried out in a similar way.

Reaction of complex 1 with excess $\mathrm{H}_{2} \mathrm{O}_{2}$. A vial was charged with a stir bar, complex 1 (0.020 $\mathrm{g}, 0.036 \mathrm{mmol})$ and $d_{6}$-acetone $(2 \mathrm{~mL})$. A solution of $\mathrm{H}_{2} \mathrm{O}_{2}(7.5 \mu \mathrm{L}, 4$ equiv, $0.14 \mathrm{mmol})$ was added to the vial via a microliter syringe while stirring. The reaction was monitored by ${ }^{1} \mathrm{H} \mathrm{NMR}$ spectroscopy, as conversion to 3, 2c and BF occurred. After 10 min. relative integration revealed the following species: 1 (6\%), 3 (60\%), 2c (34\%). Within $2 \mathrm{~h}$ signals for $2 \mathrm{c}$ had completely disappeared, but $\mathbf{3}$ persisted. Formation of the organic product BF was confirmed by comparison to the ${ }^{1} \mathrm{H}$ NMR spectrum of isolated $\mathrm{BF}$ in acetone- $d_{6}$ (see above). NMR in $\left(\mathrm{CD}_{3}\right)_{2} \mathrm{CO}$ at 600 $\mathrm{MHz}$, resonances tentatively assigned to $2 \mathrm{c}: \delta\left({ }^{1} \mathrm{H}\right)=8.10(\mathrm{~s}, 2 \mathrm{H}, \mathrm{CH}=\mathrm{N}), 6.91(\mathrm{~s}, 4 \mathrm{H}$, mes-CH), $2.11(\mathrm{~s}, 18 \mathrm{H}, \mathrm{Me})$.

Reaction of complex 3 with CO. A solution of complex $3(0.016 \mathrm{~g}, 0.030 \mathrm{mmol})$ in acetone- $d 6$ $(3 \mathrm{~mL})$ was stirred under $\mathrm{CO}$ atmosphere at room temperature for $15 \mathrm{~min}$. The solution was filtered to remove the precipitated palladium black and then monitored by ${ }^{1} \mathrm{H}$ NMR spectroscopy. Complex 3 was completely consumed and resonances for $\mathrm{MesN}=\mathrm{CH}-\mathrm{CH}=\mathrm{NMes}$ and 4,4-dimethyl-2-oxo-2H-1-benzopyran, BP (77\% yield), were observed. ${ }^{8,12}{ }^{1} \mathrm{H}$ NMR for BP $\left(\mathrm{CD}_{2} \mathrm{Cl}_{2}, 600 \mathrm{MHz}\right): \delta\left({ }^{1} \mathrm{H}\right)=7.36(\mathrm{dd}, 1 \mathrm{H}$, aryl $), 7.27(\mathrm{~m}, 1 \mathrm{H}, \operatorname{aryl}), 7.18(\mathrm{~m}, 1 \mathrm{H}$, aryl $), 7.05$ (dd, 1H, aryl), 2.62 (s, 2H, CH2), 1.35 (s, 6H, 2CH CH $_{3}$ LR-MS for BP: Found: m/z = 176.15. Calc. for $\mathrm{C}_{11} \mathrm{H}_{12} \mathrm{O}_{2}: \mathrm{m} / \mathrm{z}=176.21$.

\section{X-ray Structure Determinations ${ }^{22}$}

Data Collection and Processing. A crystal was mounted on a Mitegen polyimide micromount with a small amount of Paratone $\mathrm{N}$ oil. All X-ray measurements were made using a Bruker Kappa Axis Apex2 diffractometer at a temperature of $110 \mathrm{~K}$. The frame integration was performed using SAINT, and the resulting raw data was scaled and absorption corrected using a multi-scan averaging of symmetry equivalent data using SADABS.

Structure Solution and Refinement. The structures were solved by using the SHELXT program. All non-hydrogen atoms were obtained from the initial solution. The hydrogen atoms were 
introduced at idealized positions and were allowed to ride on the parent atom. The structural model was fit to the data using full matrix least-squares based on $F^{2}$. The calculated structure factors included corrections for anomalous dispersion from the usual tabulation. The structure was refined using the SHELXL-2014 program from the SHELX suite of crystallographic software. ${ }^{22}$ Details are given in Table $\mathrm{S} 1$ and in the CIF files.

\section{DFT Calculations}

DFT calculations were carried out for gas phase structures by using the Amsterdam Density Functional program based on the BP functional, with double-zeta basis set and first-order scalar relativistic corrections. ${ }^{23}$ Minima were confirmed by vibrational analysis; transition states were not determined. Details are given in the SI.

\section{Acknowledgments}

We thank the NSERC (Canada) for financial support.

Supporting Information Available. Table S1; crystal and refinement data for the complexes. Crystallographic data in electronic CIF form only and calculated reaction coordinates are available free of charge via the Internet at http://pubs.acs.org.

\section{References}

(1) (a) Canty, A. J. Acc. Chem. Res. 1992, 25, 83. (b) Canty, A. J. Dalton Trans. 2009, 10409. (c) Sehnal, P.; Taylor, R. J. K.; Fairlamb, I. J. S. Chem. Rev. 2010, 110, 824. (d) Xu, L.-M.; Li, B.-J.; Yang, Z.; Shi, S.-J. Chem. Soc. Rev. 2010, 39, 712. (e) Bonney, K. J.; Schoenebeck, F. Chem. Soc. Rev. 2014, 43, 6609. (f) Vicente-Hernandez, I.; Chicote, M.-T.; Vicente, J.; Bautista, D. Chem. Commun. 2016, 52, 594.

(2) (a) Haines, B. E.; Xu, H.; Verma, P.; Wang, X.-C.; Yu, J.-Q.; Musaev, D. G. J. Am. Chem. Soc. 2015, 137, 9022. (b) Hu, J.; Lan, T.; Sun, Y.; Chen, H.; Yao, J.; Rao, Y. Chem. Commun. 2015, 51, 14929. (c) Topczewski, J. J.; Sanford, M. S. Chem. Sci. 2015, 6, 70. (d) Li, Y.; Wu, Y.; Li, G.-S.; Wang, X.-S. Adv. Synth. Catal. 2014, 356, 1412. (e) Campbell, M. G.; Ritter, T. Chem. Record 2014, 14, 482. (f) Muniz, K. Angew. Chem., Int. Ed. 2009, 48, 9412. (g) Canty, A. J.; Denney, M. C.; van Koten, G.; Skelton, B. W.; White, A. H. Organometallics 2004, 23, 5432.

(3) (a) Oloo, W. N.; Zavalij, P. Y.; Vedernikov, A. N. Organometallics 2013, 32, 5601. (b) Campbell, A. N.; Stahl, S. S. Acc. Chem. Res. 2012, 45, 851. (c) Boisvert, L.; Denney, M. 
C.; Hanson, S. K.; Goldberg, K. I. J. Am. Chem. Soc. 2009, 131, 15802. (d) Scheuermann, M. L.; Goldberg, K. I. Chem. Eur. J. 2014, 20, 14556. (e) Cook, A. K.; Sanford, M. S. J. Am. Chem. Soc. 2015, 137, 3109. (f) Lyons, T. W.; Sanford, M. S. Chem. Rev. 2010, 110, 1147. (g) Vigalok, A. Acc. Chem. Res. 2015, 48, 238. (g) Geier, M. J.; Aseman, M. D.; Gagné, M. R. Organometallics 2014, 33, 4353. (h) Sberegaeva, A. V.; Zavalij, P. Y.; Vedernikov, A. N. J. Am. Chem. Soc. 2016, 138, 1446. (i) Furuya, T.; Benitez, D.; Tkatchouk, E.; Strom, A. E.; Tang, P.; Goddard, W. A. III, Ritter, T. J. Am. Chem. Soc. 2010, 132, 3793. (j) Racowski, J. M.; Dick, A. R.; Sanford, M. S. J. Am. Chem. Soc. 2009, $131,10974$.

(4) (a) Pérez-Temprano, M. H.; Racowski, J. M.; Kampf, J. W.; Sanford, M. S. J. Am. Chem. Soc. 2014, 136, 4097. (b) Camasso, N. M.; Pérez-Temprano, M. H.; Sanford, M. S. J. Am. Chem. Soc. 2014, 136, 12771. (c) Camasso, N. M.; Sanford, M. S. Science 2015, 347, 1218.

(5) Qu, F.; Khusnutdinova, J. R.; Rath, N. P.; Mirica, L. M. Chem. Commun. 2014, 50, 3036.

(6) (a) Campora, J.; Lopez, J. A.; Palma, P.; Valerga, P.; Spillner, E.; Carmona, E. Angew. Chem. Int. Ed. 1999, 38, 147. (b) Campora, J.; Gutierrez-Puebla, E.; Lopez, J. A.; Monge, A.; Palma, P.; del Rio, D.; Carmona, E. Angew. Chem. Int. Ed. 2001, 40, 3641. (c) Campora, J.; Palma, P.; Carmona, E. Coord. Chem. Rev. 1999, 193-195, 207.

(7) (a) Grice, K. A.; Scheuermann, M. L.; Goldberg, K. I. Topics in Organometallic Chemistry 2011, 35, 1. (b) Puddephatt, R. J. Angew. Chem. Int. Ed. 2002, 41, 261. (c) Bowes, E. G.; Pal, S.; Love, J. A. J. Am. Chem. Soc. 2015, 137, 16004.

(8) Koo, K.; Hillhouse, G. L.; Rheingold, A. L. Organometallics 1995, 14, 456.

(9) (a) Alsters, P. L.; Teunissen, H. T.; Boersma, J.; Spek, A. L.; van Koten, G. Organometallics 1993, 12, 4691. (b) Kamaraj, K.; Bandyopadhyay, D. Organometallics 1999, 18, 438. (c) Wadhwani, P.; Bandyopadhyay, D. Organometallics 2000, 19, 4435. (d) Bhawmick, R.; Das, P.; Neogi, D. N.; Bandyopadhyay, P. Polyhedron 2006, 25, 1177. (e) Kukowski, J. E.; Keuseman, K. J.; Smoliakova, I. P. Transition Met. Chem. 2015, 40, 877. (f) Turlington, C. R.; Morris, J.; White, P. S.; Brennessel, W. W.; Jones, W. D.; Brookhart, M.; Templeton, J. L. Organometallics 2014, 33, 4442.

(10) Figg, T. M.; Schoendorff, G.; Chilukuri, B.; Cundari, T.R. Organometallics 2013, 32, 4993. 
(11) (a) Yan, Y.; Feng, P.; Zheng, Q.-Z.; Liang, Y.-F.; Lu, J.-F.; Cui, Y.; Jiao, N. Angew. Chem. Int. Ed. 2013, 52, 5827. (b) Yamaguchi, T.; Yamaguchi, E.; Tada, N.; Itoh, A. Adv. Synth. Catal. 2015, 357, 2017. (c) Oloo, W.; Zavalij, P. Y.; Zhang, J.; Khaskin, E.; Vedernikov, A. N. J. Am. Chem. Soc. 2010, 132, 14400.

(12) Arduengo, A. J. III; Krafczyk, R.; Schmutzler, R. Tetrahedron 1999, 55, 14523.

(13) Yang, L.; Powell, D. R.; Houser, R. P. Dalton Trans. 2007, 955.

(14) (a) Chaumontet, M.; Piccardi, R.; Audic, N.; Hitce, J.; Peglion, J.-L.; Clot, E.; Baudoin, O. J. Am. Chem. Soc. 2008, 130, 15157. (b) Wilt, J. W.; Pawlikowski, W. W. Jr. J. Org. Chem. 1975, 40, 3641 .

(15) (a) Wang, W.; Zhou, R.; Jiang, Z.-J.; Wang, X.; Fu, H.-Y.; Zheng, X.-L.; Chen, H.; Li, R.-X. Eur. J. Org. Chem. 2015, 2579. (b) Gervais, C.; Anker, D.; Carret, G.; Pacheco, H. Tetrahedron 1979, 35, 745. (c) Heck, R.; Corse, J.; Grunwald, E.; Winstein, S. J. Am. Chem. Soc. 1957, 79, 3278.

(16) (a) Singh, A.; Anandhi, U.; Cinellu, M. A.; Sharp, P. R. Dalton Trans. 2008, 2314. (b) Bedford, R. B.; Bowen, J. G.; Davidson, R. B.; Haddow, M. F.; Seymour-Julen, A. E.; Sparkes, H. A.; Webster, R. L. Angew. Chem. Int. Ed. 2015, 54, 6591. (c) Allscher, T.; Klufers, P. Chem. Eur. J. 2012, 18, 10571. (d) Zhang, Y.; Puddephatt, R. J.; ManojlovicMuir, Lj.; Muir, K. W. Chem. Commun. 1996, 2599. (e) Bailey, W. D.; Luconi, L.; Rossin, A.; Yakhvarov, D.; Flowers, S. E.; Kaminsky, W.; Kemp, R. A.; Giamastiani, G.; Goldberg, K. I. Organometallics 2015, 34, 3998.

(17) Ingram, A.J.; Walker, K. L.; Zare, R. N.; Waymouth, R. M. J. Am. Chem. Soc. 2015, 137, 13632.

(18) (a) Pellarin, K. R.; McCready, M. S.; Sutherland, T. I.; Puddephatt, R. J. Organometallics 2012, 31, 8291. (b) Hazlehurst, R. J.; Pellarin, K. R.; McCready, M. S.; Puddephatt, R. J. Can. J. Chem., 2015, 93, 74-81.

(19) For example, an isomer of 7 with the $\mathrm{PdOHOH}$ group equatorial and aryl group axial, 7a, is calculated to be lower in energy (by $28 \mathrm{~kJ} \mathrm{~mol}^{-1}$ ) than 7 and would be accessible by 
pseudorotation. The oxygen atom insertion could occur in a similar way by $\mathrm{C}-\mathrm{O}$ reductive elimination from $\mathbf{7 a}$.

(20) (a) Winkler, J. R.; Gray, H. B. Struct. Bonding (Berlin) 2011, 142, 17. (b) Mayer, J. M. Comments Inorg. Chem. 1988, 8, 125. (c) Ballhausen, C. J.; Gray, H. B. Inorg. Chem. 1962, 1, 111. (d) Winkler, J. R.; Gray, H. B. In Molecular Electronic Structures of Transition Metal Complexes I; Mingos, P. D. M., Day, P., Dahl, P. J., Eds.; Springer Berlin Heidelberg: Berlin, Heidelberg, 2012, p 17. (e) Pellarin, K. R.; McCready, M. S.; Puddephatt, R. J. Organometallics 2012, 31, 6388.

(21) (a) Rogachev, A. Y.; Hoffmann, R. J. Am. Chem. Soc. 2013, 135, 3262. (b) Gossage, R. A.; Ryabov, A. D.; Spek, A. L.; Stufkens, D. J.; van Beek, J. A. M.; van Eldik, R.; van Koten, G. J. Am. Chem. Soc. 1999, 121, 2488. (c) Nabavizadeh, S. M.; Amini, H.; Rashidi, M.; Pellarin, K. R.; McCready, M. S.; Cooper, B. F. T.; Puddephatt, R. J. J. Organomet. Chem. 2012, 713, 60 .

(22) (a) Bruker-AXS, SAINT version 2013.8, 2013, Bruker-AXS, Madison, WI 53711, USA. (b) Bruker-AXS, SADABS version 2012.1, 2012, Bruker-AXS, Madison, WI 53711, USA. (c) Sheldrick, G. M., Acta Cryst. 2015, A71, 3. (d) Sheldrick, G. M., Acta Cryst. 2015, C71, 3.

(23) (a) Te Velde, G.; Bickelhaupt, F. M.; Baerends, E. J.; van Gisbergen, S.; Guerra, C. F.; Snijders, J. G.; Ziegler, T. J. Comput. Chem. 2001, 22, 931. (b) Becke, A. Phys. Rev. A 1988, 38, 3098. 


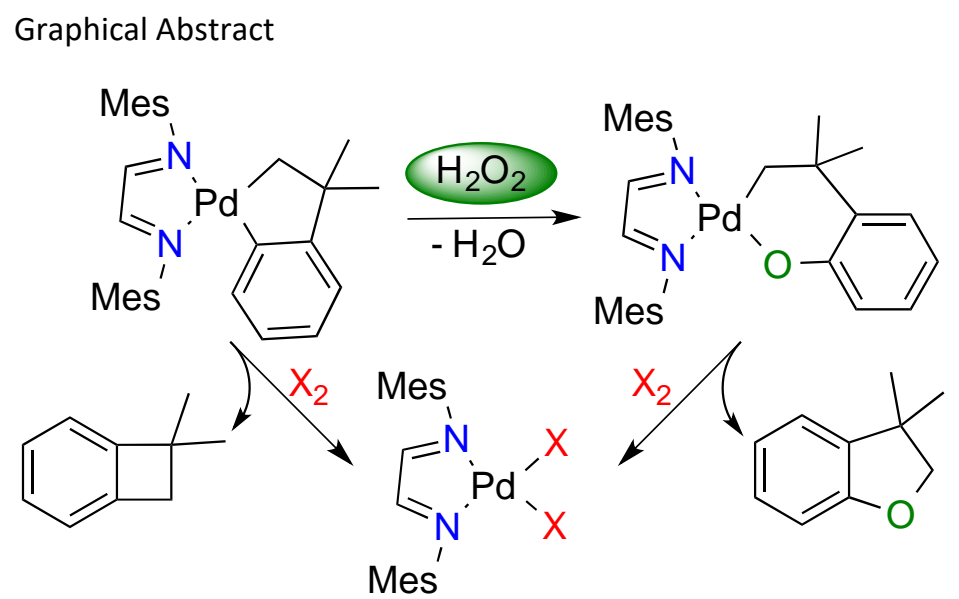

